\title{
The Pharmacology of Synapses Formed by Identified Corticocollicular Neurons in Primary Cultures of Rat Visual Cortex
}

\author{
James E. Huettner and Robert W. Baughman \\ Department of Neurobiology, Harvard Medical School, Boston, Massachusetts 02115
}

Primary cultures of neurons from the visual cortex of 7-10d-old Long Evans rats were used to study the pharmacology of synaptic transmission. Dissociated cells were grown either in mass cultures, which contained $8000-10,000$ neurons, or in miniature island cultures of 50-100 cells. Prior to dissociation, cells in layer $\mathbf{V}$ of visual cortex that project to the superior colliculus were labeled in vivo by retrograde transport of fluorescent latex microspheres-a permanent fluorescent marker. After $2 \mathrm{~d}$ to 8 weeks in culture, labeled neurons were identified by epifluorescent illumination, and electrophysiological recordings were obtained from a labeled cell and, simultaneously, from a nearby unlabeled neuron in the same field of view. The 2 neurons were stimulated sequentially by current injection and the pharmacology of evoked postsynaptic potentials (PSPs) was investigated.

In mass cultures, relatively few pairs of neurons from which we recorded were synaptically connected, although nearly every cell exhibited abundant spontaneous EPSPs and IPSPs. Neurons grown on island cultures generally did not exhibit spontaneous synaptic activity; however, stimulation of one of the cells in a pair frequently elicited a short-latency PSP in the follower neuron. Retrogradely labeled corticocollicular neurons produced only excitatory PSPs in follower cells, while unlabeled neurons were either excitatory or inhibitory. Three antagonists of excitatory amino acid receptors, kynurenic acid, piperidine dicarboxylic acid, and $\gamma$-D-glutamylglycine, completely blocked EPSPs produced by labeled corticocollicular neurons, as well as EPSPs produced by nearly all of the unlabeled excitatory cells. We have previously shown that these compounds block both $\boldsymbol{N}$-methyl-D-aspartate (NMDA)-type and non-NMDA receptors on cultured cortical neurons (Huettner and Baughman, 1986). The specific NMDA receptor antagonist 2-amino-5-phosphonovaleric acid (APV) did not alter short-latency EPSPs recorded in $1 \mathrm{~mm}$ $\mathrm{Mg}^{2+}$, but did reduce longer-latency polysynaptic activity. Since responses mediated by the NMDA receptor are known to be antagonized by $\mathbf{M g}^{2+}$ (Mayer and Westbrook, 1985), we perfused cultures with $\mathbf{M g}^{2+}$-free medium and found that the falling phase of some monosynaptic EPSPs was pro-

\footnotetext{
Received Feb. 18, 1987; revised May 20, 1987; accepted June 17, 1987.

This work was supported by the William F. Milton Fund and the Harvard University Society of Fellows (J.E.H.) and by NIH Grant EY03502 (R.W.B.). We wish to thank Bruce Bean for helpful discussions and for generously loaning us an Indec computer system. We also thank G. Fischbach, E. Furshpan, E. Kravitz, and S. McConnell for critical reading of the manuscript; Andreas Burkhalter for providing fluorescent microspheres; and Joe Gagliardi for photography.

Correspondence should be addressed to James E. Huettner, Department of Neurobiology, Harvard Medical School, 25 Shattuck St., Boston, MA 02115.

Copyright (C) 1988 Society for Neuroscience $0270-6474 / 88 / 010160-16 \$ 02.00 / 0$
}

longed. Addition of APV to $\mathrm{Mg}^{2+}$-free medium reduced the duration of the falling phase of EPSPs such that they returned to the time course obtained in $1 \mathrm{mM} \mathrm{Mg}^{2+}$. Finally, we found that IPSPs were completely blocked by 10-20 $\mu \mathrm{M}$ bicuculline methiodide and that the action potentials of inhibitory cells were significantly narrower (width at half-height $=1.0 \pm 0.14$ msec; $n=18$ ) than were action potentials of excitatory neurons $(2.0 \pm 0.47 \mathrm{msec} ; n=51)$.

Our results provide evidence that excitatory synaptic transmission between cortical neurons in culture is mediated by receptors for excitatory amino acids. In solutions containing physiological levels of $\mathbf{M g}^{2+}$, EPSPs are largely due to non-NMDA receptors, but in $\mathbf{M g}^{2+}$-free medium, most EPSPs displayed a slow, APV-sensitive component attributable to the NMDA receptor.

The CNS contains a large variety of neuronal populations that produce fast excitatory synaptic potentials in their postsynaptic target cells. The chemicals that mediate synaptic transmission in many of these populations have not yet been identified, but mounting evidence suggests that the amino acids, glutamate and aspartate, or a structural analog of these compounds, function as excitatory transmitters in a number of areas, including the cerebral cortex (Streit, 1984). Virtually all neurons in the CNS are depolarized by glutamate, and recent pharmacological studies have provided evidence for several distinct receptor sites for excitatory amino acids (Watkins and Evans, 1981; Foster and Fagg, 1984). Because glutamate and aspartate are metabolites found within all cells, it has proven difficult to identify conclusively neuronal populations that release these amino acids as transmitters. Some progress has been made with immunocytochemical (Ottersen and Storm-Mathisen, 1984; Madl et al., 1986) and autoradiographic (Baughman and Gilbert, 1981; Matute and Streit, 1985) methods of localization, but these studies must be interpreted with caution (see Discussion).

The most reliable evidence for the involvement of excitatory amino acids in particular cell populations or pathways has come from pharmacological studies of synaptic transmission in tissue slices (Collingridge et al., 1983; Crunelli et al., 1983; Cotman et al., 1986) or cell culture (Jahr and Jessell, 1985; Rothman and Samaie, 1985; Nelson et al., 1986; O'Brien and Fischbach, 1986c). Using this type of functional assay, it has been shown in several systems that glutamate receptor antagonists can block EPSPs produced by stimulation of known inputs. Although these experiments do not reveal the chemical identity of the endogenous transmitter, they demonstrate that the transmitter is exerting its postsynaptic effect via excitatory amino acid receptors. Work of this kind has provided strong evidence that an exci- 
tatory amino acid serves as the transmitter of dentate granule cells (Cotman et al., 1986), hippocampal pyramidal neurons (Collingridge et al., 1983; Rothman and Samaie, 1985), some neurons in the spinal cord (Nelson et al., 1986; O'Brien and Fischbach, 1986c), and dorsal root ganglia (Jahr and Yoshioka, 1986), as well as cells in entorhinal cortex that give rise to the perforant path (Crunclli ct al., 1983).

Several lines of evidence suggest that GABA serves as an inhibitory transmitter in the cortex. Antisera to glutamic acid decarboxylase (GAD), the GABA synthetic enzyme, as well as to GABA itself, stain several types of nonpyramidal cortical neurons (Ribak, 1978; Ottersen and Storm-Mathisen, 1984). In addition, physiological experiments have shown that GABA inhibits cortical neurons both in vivo (Krnjevic and Schwartz, 1967) and in cell culture (Dichter, 1980). Recently, immunohistochemical studies have demonstrated colocalization of GAD with immunoreactivity for a variety of neuropeptides (Hendry et al., 1984; Somogyi et al., 1984; Lin et al., 1986), although the functional significance of this colocalization is not known.

In the present study, we have examined the pharmacology of synapses formed by a specific subpopulation of rat cortical neurons in dissociated cell culture (Huettner and Baughman, 1986b). The cells were grown in relative isolation on miniature islands of astrocytes that contained a network of 50-100 neurons. Cells in layer $\mathrm{V}$ of the visual cortex that project to the superior colliculus were labeled in vivo, prior to dissociation, by retrograde transport of a permanent tracer, fluorescent latex microspheres (Katz et al., 1984). Labeled cells could be identified throughout the period in culture by epifluorescent illumination. We have examined the effects of amino acid receptor antagonists on monosynaptic EPSPs produced by labeled corticocollicular cells, as well as FPSPs produced by unlabeled, unidentified cortical neurons (Huettner and Baughman, 1986b). Our results provide evidence that corticocollicular neurons, and most other excitatory neurons in culture, release a transmitter that acts on excitatory amino acid receptors. Under certain conditions, we observed 2 components of monosynaptic EPSPs that could be attributed to kainate/quisqualate receptors and to NMDA receptors.

Portions of this work have previously been reported (Huettner and Baughman, 1986a).

\section{Materials and Methods}

Tissue culture. Cortical tissue from postnatal Long Evans rats was dissociated as previously described (Huettner and Baughman, 1986b). Briefly, blocks of visual cortex, $2 \times 3 \mathrm{~mm}$, were removed from both hemispheres of a young rat. The tissue was cut into slices and incubated for $90 \mathrm{~min}$ in balanced salt solution (BSS) containing the enzyme papain (Worthington Biochemical, Freehold, NJ). After several rinses with BSS, the tissue was triturated with a fire-polished Pasteur pipette and the cells harvested by centrifugation $(70 \times \mathrm{g}, 10 \mathrm{~min})$ through $5 \mathrm{ml}$ of BSS containing BSA $(10 \mathrm{mg} / \mathrm{ml})$ and ovomucoid $(10 \mathrm{mg} / \mathrm{ml})$. The cells were resuspended in growth medium containing Methocel (Dow Chemical Co., Midland, MI) and plated onto a confluent layer of non-neuronal cells derived from the visual cortex. We have previously shown that the majority of these non-neuronal cells possess immunoreactivity for glial fibrillary acidic protein and are thus identified as astrocytes (Huettner and Baughman, 1986b).

In some experiments, freshly dissociated neurons were plated onto islands of astrocytes that were preparcd as follows: A holc was cut in the bottom of a standard petri dish (Corning 25000) and a glass coverslip was affixed to the bottom of the dish with Sylgard (Dow). The coverslip thus forms a shallow well (Bray, 1970). A $1 \mathrm{~mm}^{2}$ grid was drawn onto the surface of the coverslip inside the petri dish with liquid Sylgard, which was dispensed under pressure from the tip of a blunt micropipette.
The Sylgard was cured overnight and the dishes were sterilized by ultraviolet irradiation for $30 \mathrm{~min}$. Droplets of sterile rat tail collagen (Bornstein, 1958) dissolved in $0.025 \%$ acetic acid were deposited into the center of each square in the grid and allowed to dry. The dishes were again irradiated for $5 \mathrm{~min}$ and dissociated cortical cells from a young rat, 1-4 dold, were plated into the wells. The cells, which included both neurons and non-neuronal cells, initially adhered to the collagen spots, but over the first week in culture non-neuronal cells multiplied and spread onto the bare glass to fill the squares. When the non-neuronal cells reached confluency, the cultures were incubated with $1-\gamma$-D-arabinofuranosyl cytosine to halt cell division. Neurons in these cultures were eliminated by a single feeding with ice-cold culture medium. Freshly dissociated neurons were then plated onto the astrocyte islands. The neurons rapidly extended processes within the squares and survived in culture for many weeks.

To visualize neuronal processes and insure that fine fibers did not cross the Sylgard boundaries that separated individual islands, several cultures were processed for localization of neurofilament-like immunoreactivity. The cultures were fixed with $4 \%$ paraformaldehyde in 0.12 M phosphate buffer, $\mathrm{pH} 7.4$, washed with Tris-buffered saline (TBS), and incubated overnight in monoclonal antibody supernatant containing $10 \%$ normal horse serum and $0.1 \%$ Triton X-100. The properties of monoclonal antibody RT-97, which exhibits selective staining of neurons in sections and in cultures, have been described by Anderton et al. (1980). Monoclonal supernatant was generously provided by Dr. J. N. Wood. Following the primary incubation, cultures were washed and incubated for $1 \mathrm{hr}$ in rabbit anti-mouse immunoglobulin (Sternberger-Meyer, Jarretsville, MD) diluted 1:40 in TBS containing 2\% BSA and $10 \%$ normal rat serum. Cultures were rinsed and incubated for 1 hr with mouse peroxidase-antiperoxidase (PAP; Sternberger-Meyer) diluted 1:40 in TBS containing $2 \%$ BSA and $10 \%$ normal rat serum. The cultures were incubated for a second cycle with rabbit anti-mouse and PAP, washed extensively with PBS, and developed with $0.1 \mathrm{M}$ phosphate buffer containing $0.1 \%$ 3-3'-diaminobenzidinetetrahydrochloride (DAB) and $0.03 \% \mathrm{H}_{2} \mathrm{O}_{2}$. The reaction was terminated with PBS, and cultures were treated with $0.1 \%$ osmium tetroxide in PBS and dehydrated.

To visualize GABA-like immunoreactivity, cultures were immersed in ice-cold $0.12 \mathrm{M}$ phosphate buffer, $\mathrm{pH} 7.4$, containing $4 \%$ glutaraldehyde and $1 \%$ paraformaldehyde. After $20 \mathrm{~min}$, the cultures were washed with TBS and stained as described above using a 1:200 dilution of rabbit antiserum raised against GABA conjugated to BSA (Ottersen and Storm-Mathiscn, 1984). The antiscrum was gencrously provided by O. P. Ottersen and J. Storm-Mathisen. Goat anti-rabbit immunoglobulin and rabbit PAP (both from Sternberger-Meyer) were used at a dilution of $1: 40$. Preimmune rabbit serum did not produce staining in our cultures.

Methods for labeling corticocollicular neurons by retrograde transport of fluorescent latex microspheres (Katz et al., 1984) have been reported previously (Huettner and Baughman, 1986b). In brief, young rats were anesthetized with halothane on postnatal day 5 or 6 and a suspension of microspheres in saline was injected bilaterally into the superior colliculi. Animals were killed for preparation of cultures on postnatal days 7-10.

Electrophysiology. After $2 \mathrm{~d}$ to 10 weeks in culture, neurons containing fluorescent latex microspheres were identified by epifluorescent illumination, and clectrophysiological recordings were obtained, either with conventional microelectrodes or with gigaseal whole-cell pipettes. Microelectrodes were pulled from thin-walled "omega-dot" tubing (Glass Company of America, Bargaintown, $\mathrm{NJ}$ ) and were filled with $0.2 \mathrm{M}$ potassium methylsulfate, $10 \mathrm{~mm}$ K-HEPES, $\mathrm{pH}$ 7.2. Whole-cell pipettes were fashioned from $100 \mu$ l Boralex pipettes (Rochester Scientific Co., Rochester, NY) and were filled with $140 \mathrm{~mm}$ potassium methylsulfate, $10 \mathrm{~mm}$ K-HEPES, pH 7.2, $0.5 \mathrm{~mm}$ K-EGTA, $5 \mathrm{~mm}$ sucrose, and $5 \mathrm{~mm}$ ATP. Signals were amplified with Getting microelectrode amplifiers and recorded on magnetic tape or digitized with an Indec data-acquisition system for analysis off line. The culture was maintained at $30^{\circ} \mathrm{C}$ and continuously perfused with BSS containing (in mM): $\mathrm{NaCl}, 137 ; \mathrm{KCl}$, 5.4; $\mathrm{KH}_{2} \mathrm{PO}_{4}, 0.4 ; \mathrm{Na}_{2} \mathrm{HPO}_{4}, 0.3$; glucose, 30; Na-HEPES, 5 (pH 7.4). Our normal recording medium contained $2 \mathrm{mM} \mathrm{CaCl}_{2}$ and $1 \mathrm{mM} \mathrm{MgSO}$; however, some experiments were performed with different levels of $\mathrm{Ca}^{2+}$ and $\mathrm{Mg}^{2+}$, as noted in the text. Recording medium to which we did not add any exogenous magnesium salts will be referred to as " $\mathrm{Mg}^{2+}$-free medium"; however, we did not determine the precise level of $\mathrm{Mg}^{2+}$ that was present as a result of contamination from other components.

Kynurenic acid and bicuculline methiodide were obtained from Sig- 

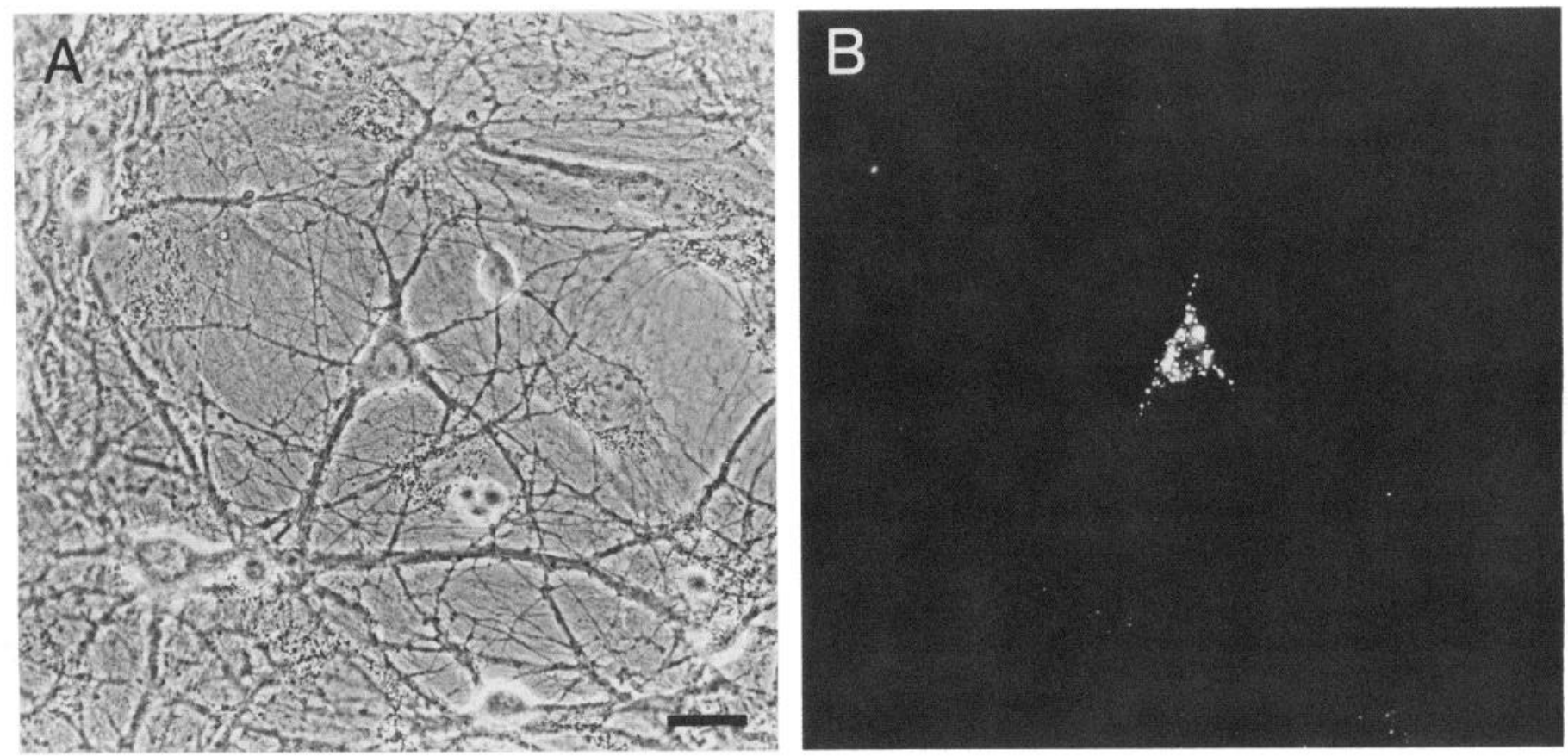

Figure 1. An identified corticocollicular neuron. Phase-contrast $(A)$ and fluorescence $(B)$ photomicrographs of the same field of view in a culture after $34 \mathrm{~d}$ in vitro. The neuron in the center of $A$ contains numerous fluorescent particles within its cytoplasm, as shown in $B$. This culture was prepared from a 7-d-old animal that had received an in vivo injection of fluorescent latex microspheres in the superior colliculus $2 \mathrm{~d}$ earlier. Bar, $30 \mu \mathrm{m}$.

ma, while 2-amino-5-phosphonovaleric acid (APV), cis-2,3-piperidinedicarboxylic acid (PDA), and $\gamma$-D-glutamylglycine (DGG) were purchased from Cambridge Research Biochemicals (Atlantic Beach, NY). These antagonists were added to the perfusion medium at $0.01-3 \mathrm{~mm}$. Over the course of our experiments, both D-(-)-APV and D,L-APV have yielded similar results. In most of the experiments reported here D,LAPV was used.

\section{Results}

Throughout the period in culture, retrogradely labeled corticocollicular neurons could be identified unambiguously for electrophysiological recordings. Figure 1 shows an example of a labeled neuron grown in a mass culture for $34 \mathrm{~d}$. Mass cultures covered an area of $80 \mathrm{~mm}^{2}$ and contained $8000-10,000$ neurons. Our preliminary recordings from pairs of neurons in mass cultures revealed that only rarely were 2 cells within the same microscopic field monosynaptically connected (see below). To improve the probability of recording from connected pairs, the number of available target cells was restricted by growing a small number of neurons on isolated islands of astrocytes (see Furshpan et al., 1976, 1986). Each island was surrounded by a hydrophobic barrier of Sylgard (Fig. $2 A$ ) that prevented both astrocytes and neuronal processes (Fig. 2, $B, C$ ) from making contact with neighboring islands. Freshly dissociated neurons were plated onto the islands at an initial density of 50-100 cells/ island $\left(1 \mathrm{~mm}^{2}\right)$. Although we have not made cell counts to quantitate neuronal survival over time, it appeared that islands containing 50-100 neurons were relatively stable for at least 34 weeks in vitro. Islands with lower initial densities generally showed a marked loss of neurons with time. In previous work (Huettner and Baughman, 1986b), we found that retrogradely labeled corticocollicular cells made up 1-2\% of all neurons in culture. Thus, each island of 50-100 cells contained, on average, one labeled corticocollicular neuron.

\section{Electrophysiology}

Electrophysiological recordings were obtained from 48 neurons in mass cultures, including 14 retrogradely labeled corticocollicular neurons, and from 216 neurons grown in island cultures, of which 62 were corticocollicular cells. All of the cells included in this study had resting potentials of -50 to $-80 \mathrm{mV}$, and most displayed overshooting action potentials throughout the period of recording. Simultaneous recordings from pairs of cells were routinely maintained for 40-60 min and, in favorable cases, for several hours. In our normal recording medium, which contained $2 \mathrm{mM} \mathrm{Ca}^{2+}$ and $1 \mathrm{mM} \mathrm{Mg}^{2+}$, virtually every neuron in the mass cultures received spontaneous EPSPs and IPSPs. Many EPSPs exceeded threshold and caused the neuron to fire one or more action potentials. Most neurons in mass cultures also received complex barrages of superimposed postsynaptic potentials, indicating that numerous presynaptic inputs to the cell were firing in unison. When recording from pairs of neurons in mass cultures, we frequently observed that both cells received EPSPs and IPSPs simultaneously, suggesting that both were innervated by a third cell in the dish. Only infrequently, however, was there a synaptic connection between the 2 neurons from which we recorded ( $8 / 24$ pair). In those cases in which synaptic connections were found, the postsynaptic response was a simple, monophasic EPSP or IPSP with a latency of 1.2-2.5 msec.

In contrast to those in the mass cultures, neurons grown on astrocyte islands exhibited only low levels of spontaneous synaptic activity. As a measure of spontaneous activity, we counted the number of suprathreshold EPSPs per unit of time in several representative recordings from mass and island cultures. The cells in mass cultures displayed an average of $72 \pm 40(n=10)$ suprathreshold EPSPs per minute, while the value for neurons 

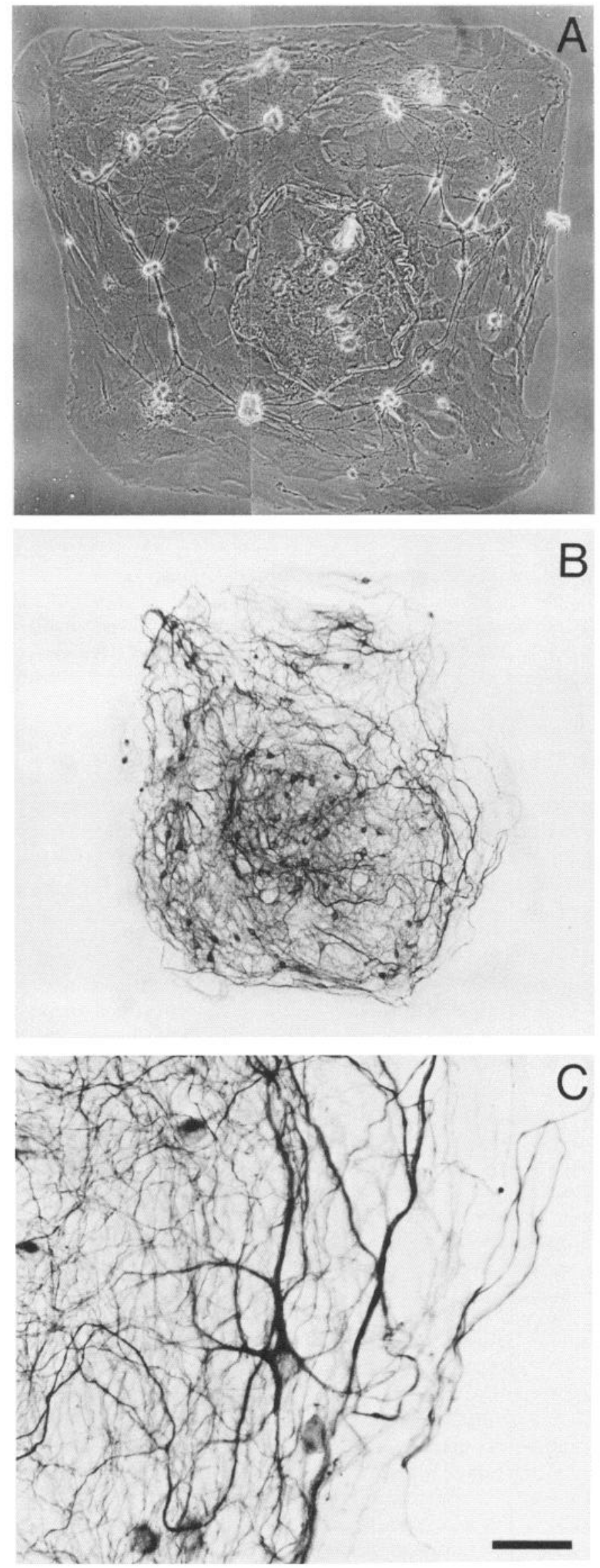
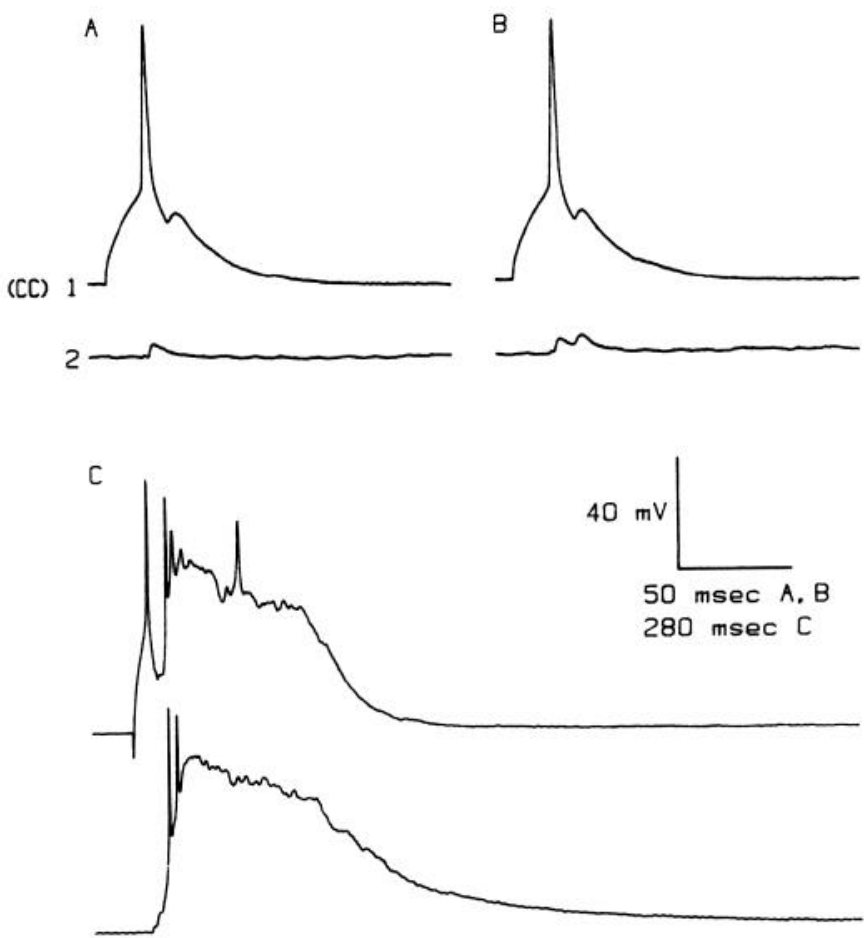

Figure 3. Evoked postsynaptic potentials recorded in island cultures. $A$ and $B$, EPSPs recorded after $2 \mathrm{~d}$ in vitro. The driver neuron, cell 1 , was a labeled corticocollicular neuron, while the follower, cell 2, was not labeled. In both $A$ and $B$ cell 1 was stimulated with depolarizing current to fire a single action potential. $A$, A monosynaptic EPSP was evoked in cell 2 . $B$, In this sweep, cell 2 displayed a monosynaptic EPSP, as well as a longer-latency EPSP that resulted from polysynaptic excitation. In both $A$ and $B$ cell 1 also received a polysynaptic EPSP. The resting potential of cell 1 was $-66 \mathrm{mV}$, while that of cell 2 was -62 $\mathrm{mV}$. C, A depolarizing burst of polysynaptic excitation recorded after $19 \mathrm{~d}$ in vitro. The cell in the upper trace was stimulated by current injection to fire a single action potential. Neither cell in $C$ was retrogradely labeled. The resting potential of the driver neuron was -73 $\mathrm{mV}$, while the resting potential of the follower cell was $-61 \mathrm{mV}$. In this and all subsequent figures, traces recorded from labeled corticocollicular neurons are marked $(C C)$.

in island cultures was $7 \pm 8(n=10)$. Although the level of spontaneous synaptic activity in island cultures was low, recordings from pairs of neurons revealed that most pairs were synaptically connected. Synaptic potentials were first observed $36-48 \mathrm{hr}$ after cells had been plated. Figure $3, A, B$, shows recordings obtained from a labeled corticocollicular neuron (cell 1) and from an unlabeled neuron (cell 2) after $2 \mathrm{~d}$ in vitro. Stimulation of the labeled neuron reliably evoked an EPSP in cell 2 at a latency of $1.7 \mathrm{msec}$. Both the driver and the follower neuron occasionally received synaptic potentials at a longer la-

Figure 2. Miniature island cultures. The phase-contrast photomicrograph $(A)$ shows an island culture $18 \mathrm{~d}$ after neurons were plated. Nonneuronal cells have multiplied to fill the square region of exposed glass but have not attached to the Sylgard boundary, which appears as a smooth border along the edge of the micrograph. Approximately 60 neurons form a network on top of the flat, non-neuronal cells. $B$ and $C$, Immunohistochemical localization of neurofilament-like immunoreactivity in a different island culture $25 \mathrm{~d}$ after neurons were plated. $B$ shows a low-power view of the whole island, which contained approximately 75 neurons. In $C$, a higher-power view of the lower-right-hand corner of the island is shown in the same orientation as in $B$. Bar: $100 \mu \mathrm{m}(A)$; $180 \mu \mathrm{m}(B) ; 43 \mu \mathrm{m}(C)$. 
Table 1. Postsynaptic responses evoked by labeled corticocollicular cells and by unlabeled, unidentified cortical neurons

\begin{tabular}{lclllc} 
Driver & Total no. & $\begin{array}{l}\text { Mono- } \\
\text { synaptic } \\
\text { EPSP }\end{array}$ & $\begin{array}{l}\text { Mono- } \\
\text { synaptic } \\
\text { IPSP }\end{array}$ & $\begin{array}{l}\text { Poly- } \\
\text { synaptic } \\
\text { excitation }\end{array}$ & $\begin{array}{l}\text { No } \\
\text { response }\end{array}$ \\
\hline Corticocollicular neurons & 62 & 34 & 0 & 21 & 7 \\
Unlabeled neurons & 154 & 82 & 21 & 36 & 15
\end{tabular}

All entries represent the number of driver neurons that produced each type of postsynaptic response. Postsynaptic responses were classified as described in the text. All of the recordings were obtained from neurons on island cultures.

tency, produced via polysynaptic circuits. In more mature cultures, this polysynaptic activity could become cxtremely robust. Depolarizing bursts of synaptic input $30-50 \mathrm{mV}$ in amplitude and several hundred milliseconds in duration were commonly observed. Figure $3 C$ shows an evoked burst of synaptic activity in a pair of neurons grown on an astrocyte island for $19 \mathrm{~d}$. A depolarizing current pulse initially triggered a single action potential in the driver neuron, which is shown in the upper trace. The follower cell, shown in the bottom trace, displayed an EPSP $1.9 \mathrm{msec}$ after the peak of the driver's action potential and, at longer latency, both neurons exhibited strong depolarizations that gradually returned to baseline after $600-900 \mathrm{msec}$. The amplitude and time course of the long-latency activity varied from trace to trace. The activity was suppresssed or abolished by increasing the concentration of $\mathrm{Ca}^{2+}$ and $\mathrm{Mg}^{2+}\left(5 \mathrm{mM} \mathrm{Ca} \mathrm{Ca}^{2+} / 3\right.$ $\mathrm{mM} \mathrm{Mg}^{2+}$ ) or by adding 5-10 nM TTX to the bath. These 2 treatments should elevate the spike threshold of follower cells (Frankenhaeuser and Hodgkin, 1957; Yellen, 1984). Slightly higher levels of TTX (15-30 nM) completely blocked synaptic transmission, even though action potentials could still be elicited in the cell soma, and at TTX levels greater than $30 \mathrm{~nm}$ all spiking was abolished. Transmission also was abolished by $2-3 \mathrm{~mm}$ $\mathrm{Co}^{2+}$ and by medium containing low $\mathrm{Ca}^{2+}$ and high $\mathrm{Mg}^{2+}(0.2$ $\mathrm{mm} \mathrm{Ca}{ }^{2+} / 10 \mathrm{~mm} \mathrm{Mg}^{2+}$ ). In most cells, it was possible to titrate the level of $\mathrm{Ca}^{2+}$ and $\mathrm{Mg}^{2+}$ or of TTX to completely eliminate the long-latency synaptic activity without blocking the shortlatency monosynaptic potentials. The following evidence suggested that synaptic potentials with latencies of $1-2.5 \mathrm{msec}$ were, in fact, monosynaptic. (1) The shortest latencies observed for both EPSPs and IPSPs were 1-1.2 msec. (2) The short-latency PSPs could follow brief trains of repetitive stimulation at 10 $50 \mathrm{~Hz}$, while longer-latency components did not. (3) The amplitude of short-latency PSPs underwent a gradual reduction and recovery as antagonists were introduced and washed out of the perfusion medium. Longer-latency components generally were abolished and returned in an all-or-none fashion.

We classified the postsynaptic response produced by any given driver neuron into one of the following categories: (1) monosynaptic EPSP, (2) monosynaptic IPSP, (3) stimulus-locked polysynaptic input, but no monosynaptic connection, (4) null. Table 1 shows the results for driver neurons in island culturcs, including retrogradely labeled corticollicular cells, as well as unlabeled, unidentified neurons. The majority of the corticocollicular neurons produced monosynaptic EPSPs in their follower cells. A smaller percentage evoked only polysynaptic activity or no response, but in no case did a labeled neuron elicit a monosynaptic IPSP. In contrast, many of the unlabeled cortical cells produced IPSPs in their followers. These results suggest that the corticocollicular neurons in culture made only excitatory synapses with their follower cells.

\section{Pharmacology of excitatory synapses}

Cortical neurons both in vivo (Hayashi, 1954; Krnjevic and Phillis, 1963) and in culture (Huettner and Baughman, 1986b) are depolarized by the amino acids glutamate and aspartate. In previous work (Huettner and Baughman, 1986b), we found that essentially all of the neurons in our cultures expressed both NMDA and non-NMDA receptors for excitatory amino acids (see Discussion). In order to test the role that these receptors play in excitatory synaptic transmission, we examined the effect of amino acid receptor antagonists on monosynaptic EPSPs. Figure 4 demonstrates the action of kynurenic acid, PDA, and DGG. These 3 antagonists are known to block responses mediated by both NMDA and non-NMDA receptors (Davies and Watkins, 1981; Davies et al., 1981a; Ganong et al., 1983; O'Brien and Fischbach, 1986b). In Figure 4 the driver neuron, cell 1, is a retrogradely labeled corticocollicular neuron that reliably produces an EPSP in the follower cell (cell 2) at a latency of 2.1 msec. Addition of $3 \mathrm{~mm}$ kynurenic acid to the perfusion medium gradually reduces the amplitude of the EPSP as the concentration reaches equilibrium and, after 2-3 min, a complete block is achieved (Fig. 4B). The EPSP slowly recovers as the drug is washed out with fresh perfusion medium. PDA and DGG block the EPSP in a similar fashion. The 3 antagonists do not alter the resting potential or input resistance of neurons, and their action has been shown by other investigators to be postsynaptic (Jahr and Jessell, 1985; Cotman et al., 1986; Nelson et al., 1986).

In the course of our experiments, the effects of one or more of these 3 antagonists have been tested on EPSPs evoked by 29 labeled drivers and 72 unlabeled excitatory driver neurons. All of the EPSPs produced by labeled corticollicular neurons as drivers were reduced or abolished by the 3 antagonists. Significant blockade began for all 3 drugs at concentrations of 100 $250 \mu \mathrm{M}$, with complete antagonism occurring between 1-3 mм. Similarly, the EPSPs evoked by unlabeled excitatory cortical cells were also blocked by each of the 3 antagonists, with the exception of a single case that was not reduced by either $1 \mathrm{~mm}$ kynurenic acid of $1 \mathrm{~mm}$ PDA. At present, we do not know whether this exception resulted from a technical artifact or represents a small subpopulation of excitatory cells whose synapses are not mediated by excitatory amino acids. In any case, our data provide strong evidence that a large majority of the excitatory cortical neurons in cultures, including the retrogradely labeled corticocollicular cells, evoke monosynaptic EPSPs via a transmitter that acts on excitatory amino acid receptors.

As mentioned above, kynurenic acid, PDA, and DGG are relatively nonselective in that they block both the NMDA and non-NMDA subclasses of amino acid receptors. To assess the contribution that each of these receptor subtypes made to the postsynaptic response, we examined the effect of the specific 


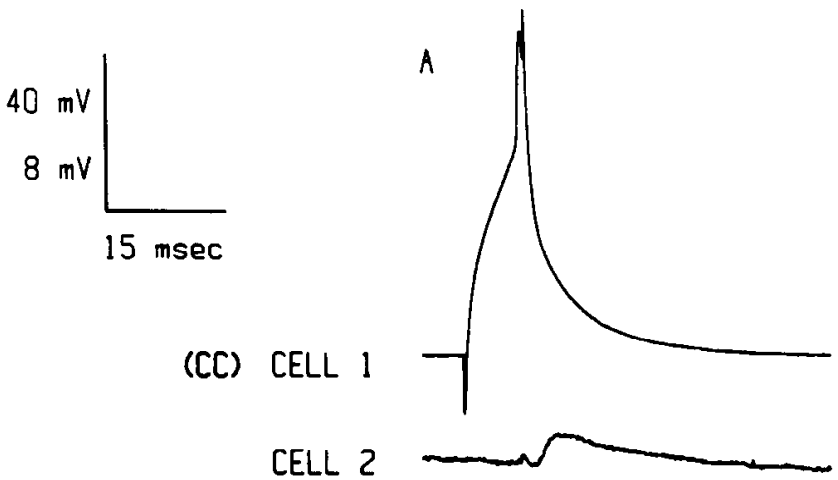

CELL 2
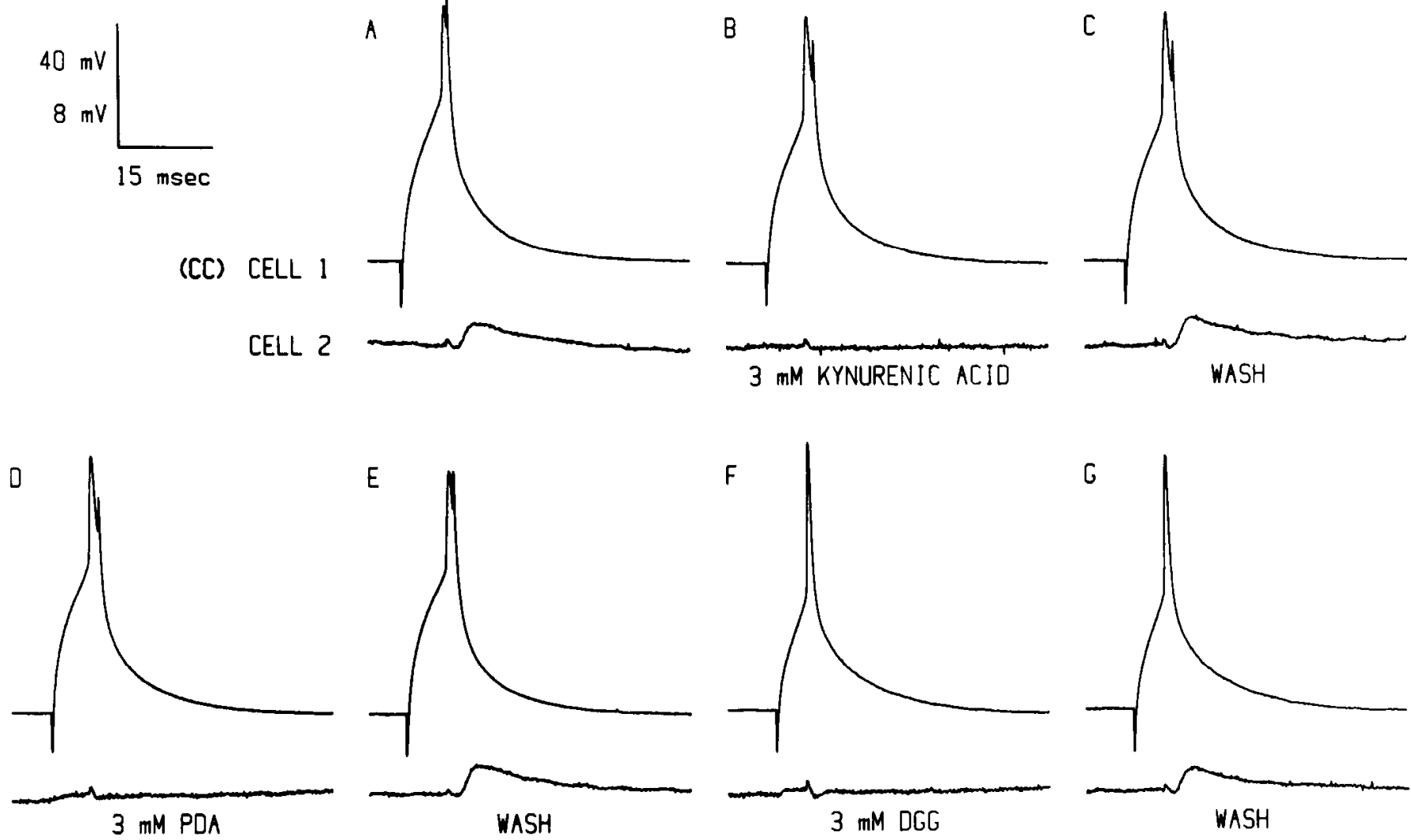

Figure 4. Effects of kynurcnic acid, PDA, and DGG on monosynaptic EPSPs evoked by stimulation of a labeled corticocollicular neuron. $A$, Stimulation of cell 1 produced a monosynaptic EPSP in cell 2. Superfusion of the culture with 3 mM kynurenic acid $(B)$, PDA $(D)$, or DGG $(F)$ significantly reduced the EPSP. The EPSP recovered when the culture was perfused with normal recording medium after each drug $(C, E$, and $G)$. The recurdings were obtained from neurons on an island culture $10 \mathrm{~d}$ after plating. The resting potential of cell 1 was $-71 \mathrm{mV}$, while that of cell 2 was $-74 \mathrm{mV}$.

NMDA receptor antagonist APV (Davies et al., 1981b). In agreement with other studies (Collingridge ct al., 1983; Crunelli et al., 1983; Davies and Watkins, 1983; Jahr and Yoshioka, 1986), we found that APV had virtually no effect on monosynaptic EPSPs in solutions containing physiological levels of $\mathrm{Ca}^{2+}$ and $\mathrm{Mg}^{2+}$ (see below, Fig. 7 and Table 2); however, it did consistently reduce polysnaptic excitation. Figure 5 illustrates the effect of kynurenic acid and of APV on a burst of postsynaptic activity recorded in medium containing $1 \mathrm{~mm} \mathrm{Mg}^{2+}$. In $50 \mu \mathrm{M}$ APV (Fig. 5D), the monosynaptic EPSP, as well as several of the earliest potentials due to polysynaptic circuits, was not blocked; however, longer-latency polysynaptic activity was substantially reduced. In contrast, synaptic transmission was completely blocked by $3 \mathrm{~mm}$ kynurenic acid (Fig. $5 B$ ). Mayer and Westbrook (1985) have shown that the current elicited in central neurons via the NMDA receptor is reduced by physiological levels of $\mathrm{Mg}^{2+}$. The action of $\mathrm{Mg}^{2+}$ is voltage-dependent (Mayer and Westbrook, 1985) and is thought to result from a direct blockade of the ion channel controlled by the NMDA receptor (Nowak et al., 1984). At normal resting potentials of -60 to $-80 \mathrm{mV}$, responses to NMDA are substantially reduced by $\mathrm{Mg}^{2+}$, but the blockade is progressively relieved as the membrane is depolarized to -10 to $-20 \mathrm{mV}$ (Mayer and Westbrook, 1985). Recently, several laboratories have provided evidence that removal of $\mathrm{Mg}^{2+}$ from the bathing solution or depolarization of the postsynaptic follower cell can unmask an APV-sensitive component of monosynaptic EPSPs (Dale and Roberts,
1985; Herron et al., 1985; Dale and Grillner, 1986; Thompson, 1986).

In our hands, depolarization or hyperpolarization of follower cells with direct current in medium containing $1 \mathrm{mM} \mathrm{Mg}^{2+}$ did not reveal any novel components of the EPSPs (cf. Fig. 6 of Thompson, 1986). The amplitude of evoked EPSPs increased when follower cells were hyperpolarized below their normal resting potentials, and decreased as the follower neurons were depolarized. In 2 cells it was possible to reverse the polarity of the EPSPs by depolarization. The reversal potentials in these cases were near $0 \mathrm{mV}$ (Fig. 6). In 11 additional neurons, the EPSP amplitude increased linearly with hyperpolarization and decreased linearly with small depolarizations. With larger depolarizations, the input resistance of these cells decreased to a low level and reversal of the EPSP was not obtained. In contrast to membrane polarization, perfusion of cultures with $\mathrm{Mg}^{2+}$-free medium often resulted in a change in the time course of monosynaptic EPSPs. Figure 7 shows several examples of EPSPs recorded either in normal medium containing $1 \mathrm{mM} \mathrm{Mg}^{2+}$ (trace $1, A-C$ ) or in $\mathrm{Mg}^{2+}$-free medium (trace 2, $A-C$ ). EPSPs recorded while cells were bathed in $\mathbf{M g}^{2+}$-free medium typically had initial rising phases that were similar to those obtained in normal medium. The falling phase of EPSPs recorded in most follower neurons, however, was distinctly prolonged or augmented (Fig. $7, B, C)$ in $\mathrm{Mg}^{2}$-free medium, suggesting the addition of a slow component to the EPSP that was mediated by NMDA receptors. Consistent with this hypothesis, we found that the addition of 


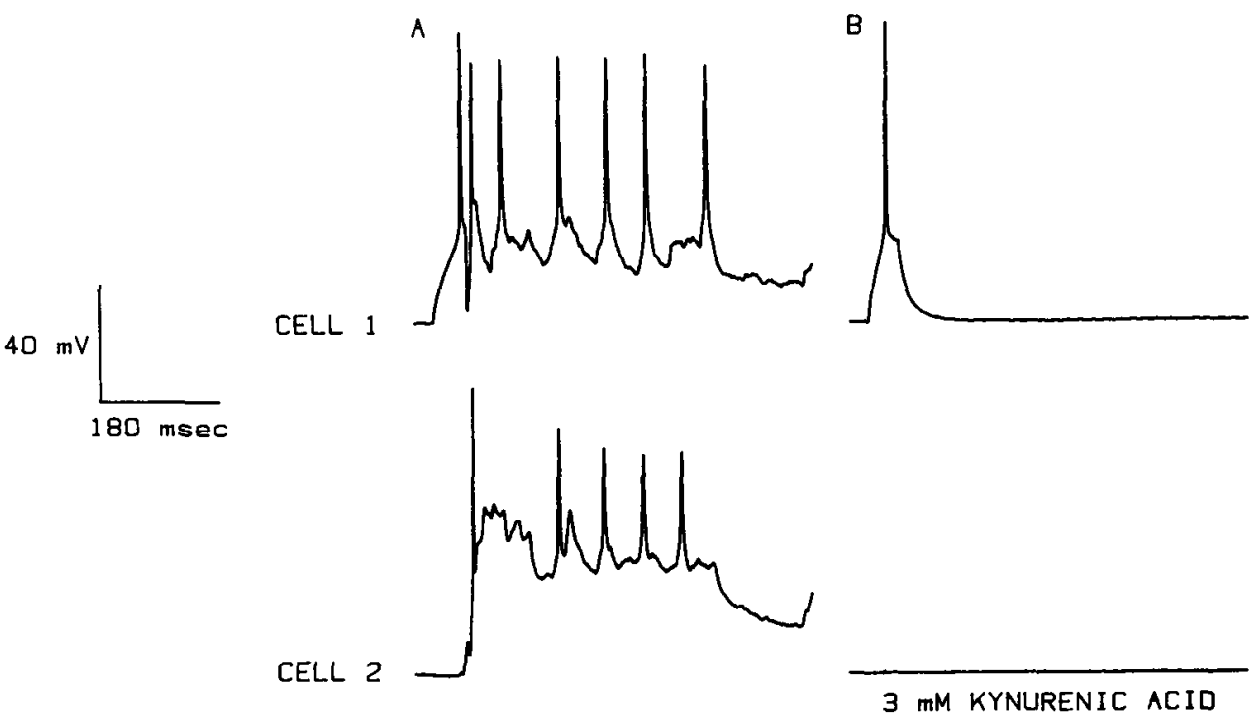

Figure 5. Effects of kynurenic acid and APV on PSPs recorded in medium containing $1 \mathrm{mM} \mathrm{Mg}^{2+}$. A, Stimulation of cell 1 evoked a monosynaptic EPSP in cell 2 and produced a barrage of polysynaptic activity in both cells. $B$, Perfusion of the culture with $3 \mathrm{~mm}$ kynurenic acid reversibly blocked transmission. In $50 \mu_{M} D, L-A P V(D)$, the level of polysynaptic excitation was signifcantly reduced, although the monosynaptic EPSP and several of the earliest potentials due to polysynaptic circuits were not abolished. The recordings were obtained from 2 unlabeled neurons on an island culture $23 \mathrm{~d}$ after plating. The resting potential of cell 1 was $-81 \mathrm{mV}$, while that of cell 2 was $-77 \mathrm{mV}$.
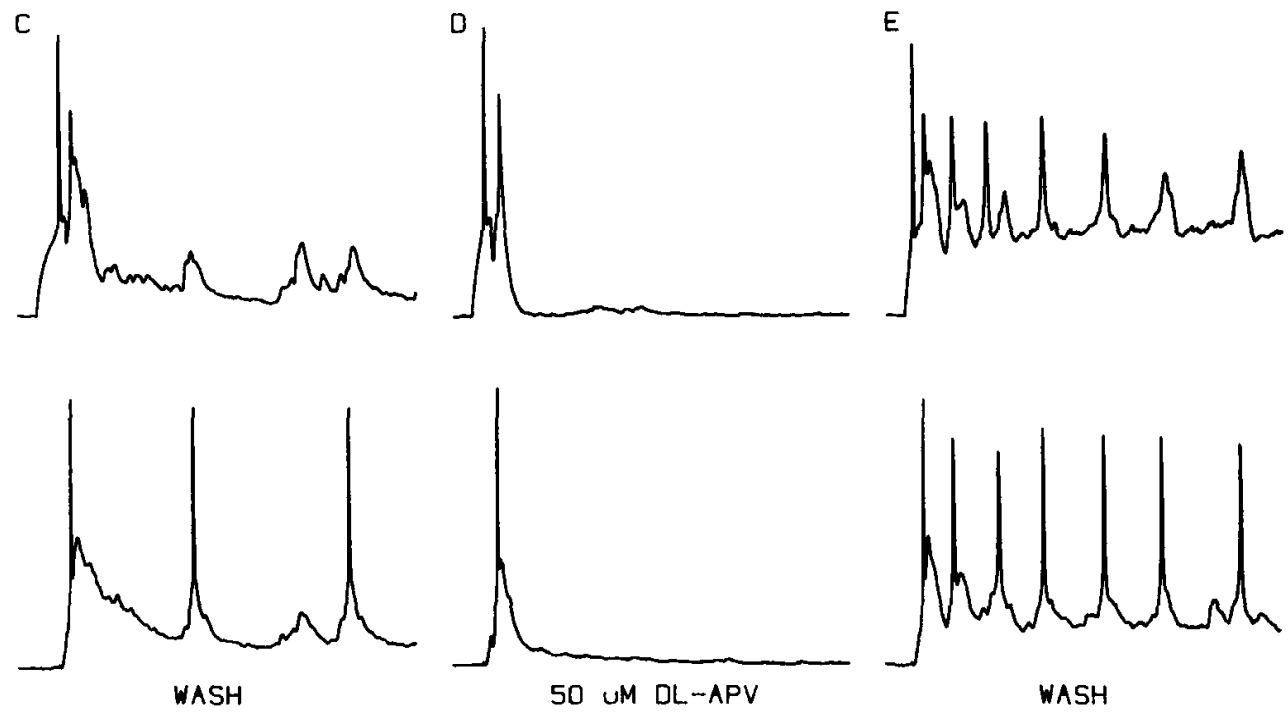

20-50 $\mu \mathrm{M}$ DL-APV to $\mathrm{Mg}^{2+}$-free medium reduced the duration of the EPSPs (trace 3, $A-C$ ) such that they returned to the time course obtained in $1 \mathrm{~mm} \mathrm{Mg}{ }^{2+}$. As described above, the addition of APV to medium containing $1 \mathrm{mM} \mathrm{Mg}^{2+}$ did not alter the monosynaptic EPSPs (trace 4, $A-C$ ). The magnitude of the APVsensitive component of the EPSP present in $\mathrm{Mg}^{2+}$-free medium varied substantially from cell to cell. The neuron shown in Figure $7 \mathrm{~A}$ showed the smallest effect of removing $\mathrm{Mg}^{2+}$ that we have observed, while the cell in Figure $7 C$ showed one of the largest augmentations in $\mathrm{Mg}^{2+}$-free medium. We do not know the reason for this variability in the size of the APV-sensitive component; however, it was clear that most EPSPs showed some degree of prolongation in $\mathrm{Mg}^{2+}$-free medium and that APV completely antagonized this effect (Table 2).

\section{GABA neurons}

Dichter and co-workers (Dichter, 1980; Snodgrass et al., 1980; White et al., 1980) have provided extensive evidence that GABA serves as an inhibitory transmitter in primary cultures prepared from embryonic rat cerebral cortex. In earlier work (Huettner and Baughman, $1986 \mathrm{~b}$ ), we found that $20-25 \%$ of the neurons in our cultures exhibit GAD-like immunoreactivity and are thus likely to be inhibitory. To confirm the presence of a subpopulation of neurons containing GABA, we used a well-characterized antiserum (Ottersen and Storm-Mathisen, 1984) to detect GABA-like immunoreactivity. As shown in Figure 8, the antiserum stained a subset of neurons and did not label the background layer of astrocytes. The DAB reaction product was found throughout the cell soma, including the nucleus, of all positive neurons. Staining was nearly continuous along positive processes, such that in relatively sparse regions of the cultures it was possible to trace the full arborization of individual cells. Both axons and dendrites appeared to be stained with equal intensity, and axon-like processes possessed numerous varicosities that were found in close contact with the somata and processes of unstained cortical neurons (Fig. 8, arrowhead). Cell counts revealed that $24 \pm 5 \%(n=9)$ of all neurons in our cultures possessed GABA-like immunoreactivity. 
A

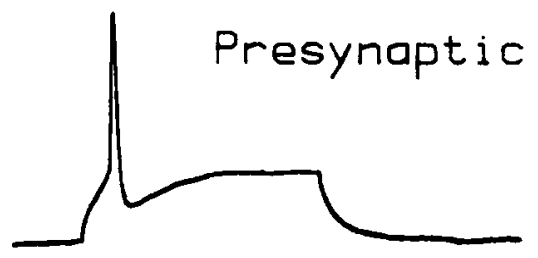

(CC) Postsynaptic
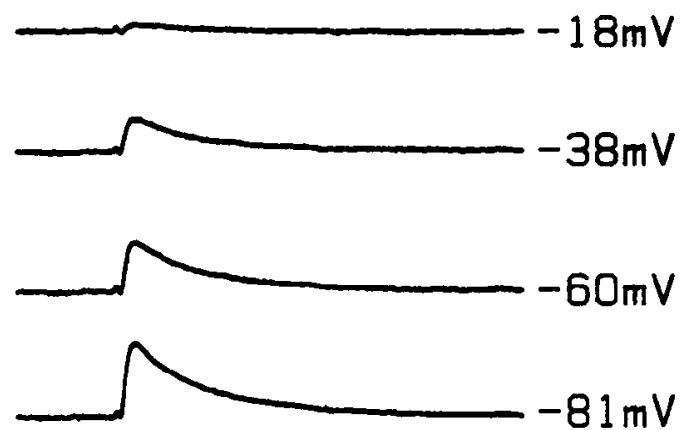

Q

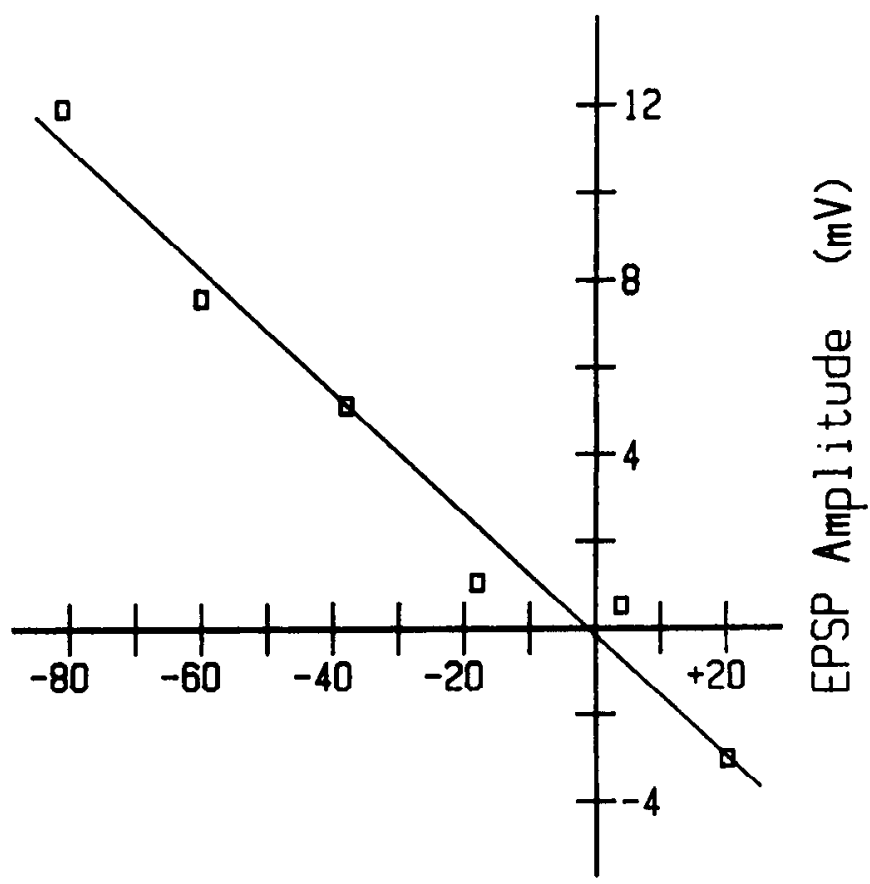

Membrane Potential (mV)

Figure 6. Amplitude of a monosynaptic EPSP as a function of membrane potential. In part $(A)$, the presynaptic neuron (top trace) was stimulated to fire action potentials by injection of depolarizing current. A single presynaptic action potential is illustrated. The time course of the EPSP at 6 different membrane potentials is shown in the 6 lower traces in A. Steady, direct current was injected to depolarize or hyperpolarize the postsynaptic neuron, which was a labeled corticocollicular neuron, from its normal resting potential of $-65 \mathrm{mV}$. The falling phase of the EPSP could be fitted well by a single exponential. The time constant of decay was relatively unchanged over the range of membrane potentials tested $(\tau=13.9$ msec at $-81 \mathrm{mV} ; 12.9 \mathrm{msec}$ at $-60 \mathrm{mV} ; 13.6 \mathrm{msec}$ at $-38 \mathrm{mV} ; 12.7 \mathrm{msec}$ at $+20 \mathrm{mV}$ ). In $B$, the peak EPSP amplitude at each membrane potential shown in $A$ is plotted as a function of membrane potential. The straight line represents a least-squares fit to the data points. The recordings were obtained from neurons on an island culture $17 \mathrm{~d}$ after plating.

\section{Pharmacology of inhibitory synapses}

Recent pharmacological experiments have provided evidence that GABA can act on 2 distinct receptors. Conventional IPSPs are mediated by the $\mathrm{GABA}_{\mathrm{A}}$ receptor, which is antagonized by bicuculline and controls a channel permeable to $\mathrm{Cl}^{-}$(Barker and Ransom, 1978; Choi and Fischbach, 1981). The GABA receptor modulates voltage-activated currents and is not blocked by bicuculline (Dunlap and Fischbach, 1978; Newberry and Nicoll, 1985). In addition, immunohistochemical studies (Hen-

Table 2. Effect of APV on the amplitude and width at half-amplitude of monosynaptic EPSPs recorded in $1 \mathrm{mM} \mathrm{Mg}^{2+}$ and in $\mathrm{Mg}^{2+}-$ free medium

\begin{tabular}{|c|c|c|c|c|c|c|c|c|c|c|}
\hline \multirow[b]{2}{*}{$\begin{array}{l}\text { Cell } \\
\text { pair }\end{array}$} & \multirow[b]{2}{*}{$\begin{array}{l}\text { Days } \\
\text { in vitro }\end{array}$} & \multirow[b]{2}{*}{$\begin{array}{l}\text { Resting } \\
\text { potential } \\
(\mathrm{mV})\end{array}$} & \multicolumn{2}{|c|}{$\mathrm{Mg}^{2+}(1 \mathrm{~mm})$} & \multicolumn{2}{|c|}{$\mathrm{Mg}^{2+}(1 \mathrm{~mm})+\mathrm{APV}$} & \multicolumn{2}{|c|}{$\mathrm{Mg}^{2+}$-free } & \multicolumn{2}{|c|}{$\mathrm{Mg}^{2+}$-free + APV } \\
\hline & & & $\begin{array}{l}\text { Ampli- } \\
\text { tude } \\
(\mathrm{mV})\end{array}$ & $\begin{array}{l}\text { Width } \\
\text { (msec) }\end{array}$ & $\begin{array}{l}\text { Ampli- } \\
\text { tude } \\
\text { (mV) }\end{array}$ & $\begin{array}{l}\text { Width } \\
\text { (msec) }\end{array}$ & $\begin{array}{l}\text { Ampli- } \\
\text { tude } \\
(\mathrm{mV})\end{array}$ & $\begin{array}{l}\text { Width } \\
(\mathrm{msec})\end{array}$ & $\begin{array}{l}\text { Ampli- } \\
\text { tude } \\
(\mathrm{mV})\end{array}$ & $\begin{array}{l}\text { Width } \\
\text { (msec) }\end{array}$ \\
\hline $1^{a}$ & 10 & -72 & 4.9 & 20.5 & 5.0 & 25.6 & 4.8 & 26.7 & 5.0 & 21.5 \\
\hline 2 & 14 & -76 & 5.1 & 36.9 & 5.2 & 35.9 & 5.4 & 76.9 & 5.1 & 29.7 \\
\hline 3 & 10 & -73 & 1.8 & 61.5 & 1.9 & 63.6 & 2.9 & 129 & 1.7 & 65.6 \\
\hline 4 & 7 & -76 & 5.8 & 23.8 & - & - & 5.8 & 43.6 & 5.9 & 23.1 \\
\hline 5 & 11 & -78 & 4.2 & 17.8 & 3.9 & 20.6 & 4.4 & 53.3 & 4.3 & 21.8 \\
\hline $6^{h}$ & 10 & -75 & 1.5 & 20.5 & - & - & 1.6 & 50.6 & 1.4 & 21.9 \\
\hline 7 & 16 & -67 & 3.3 & 25.1 & 3.4 & 25.3 & 3.4 & 55.3 & 3.2 & 23.2 \\
\hline 8 & 25 & -63 & 2.7 & 26.7 & 2.5 & 28.0 & 2.8 & 46.5 & 2.7 & 27.3 \\
\hline
\end{tabular}

For each condition, 10 EPSPs were averaged and the peak amplitude and width at half of the peak amplitude were measured. In order to suppress polysynaptic inputs to the follower cells, TTX was added to the perfusion medium at 5-10 nM. The resting potential of the follower neuron is given for each pair. The EPSP from cell pair 1 is shown in Figure 7A, while the EPSPs from pairs 2 and 3 are shown in Figure 7, $B$ and $C$, respectively.

${ }^{a}$ The follower neuron in cell pair 1 was a retrogradely labeled corticocollicular cell.

$b$ The driver neuron in cell pair 6 was a labeled corticocollicular neuron. 
Figure 7. Effect of APV on 3 different monosynaptic EPSPs $(A-C)$ recorded in medium containing $1 \mathrm{mM} \mathrm{Mg}^{2+}$ or in $\mathrm{Mg}^{2+}$-free medium. Trace $1, A-C$, shows the EPSP recorded in $1 \mathrm{mM} \mathrm{Mg}^{2+}$ at the beginning of the experiment. The culture was then perfused with $\mathbf{M g}^{2+}$-free medium (trace 2) and then with $\mathrm{Mg}^{2+}$ free medium containing $50 \mu \mathrm{M}$ D,L-APV (trace 3). Finally, the cultures were perfused with $50 \mu \mathrm{M} \mathrm{D}, \mathrm{L}-\mathrm{APV}$ in medium containing $1 \mathrm{mM} \mathrm{Mg}^{2+}$ (trace 4). At the bottom of each panel the 4 traces are superimposed (e.g., in $A, 1-4$ ) for clearer comparison. Each trace is the average of 10 individual records. In each experiment, 5-10 nM TTX was added to the perfusion medium in order to suppress polysynaptic inputs to the follower neuron. The EPSP in $A$ was recorded from a labeled corticocollicular follower cell (resting potential, $-72 \mathrm{mV}$ ) $10 \mathrm{~d}$ after plating. The driver neuron in $A$ was not labeled. In $B$, the recordings were obtained $14 \mathrm{~d}$ after plating, and both the driver and follower cells were unlabeled. The resting potential of the follower was $-76 \mathrm{mV}$. The EPSP in $C$ was recorded $10 \mathrm{~d}$ after plating. Both the driver and the follower were unlabeled. The resting potential of the follower cell was $-73 \mathrm{mV}$.

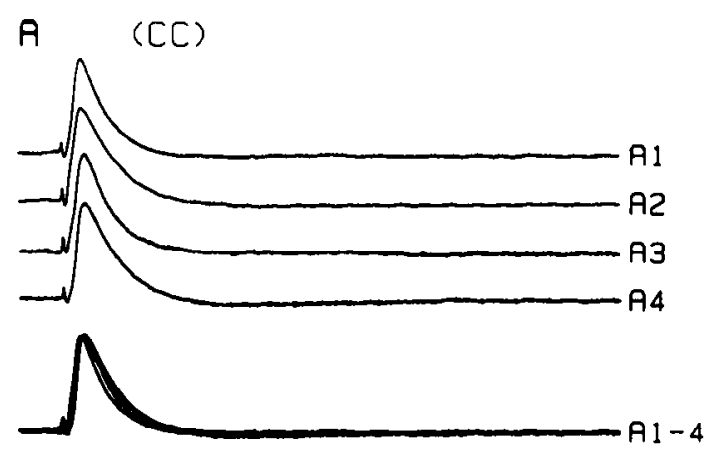

$8 m V(A, B)$

$4 m \vee(C)$

$90 \mathrm{msec}$
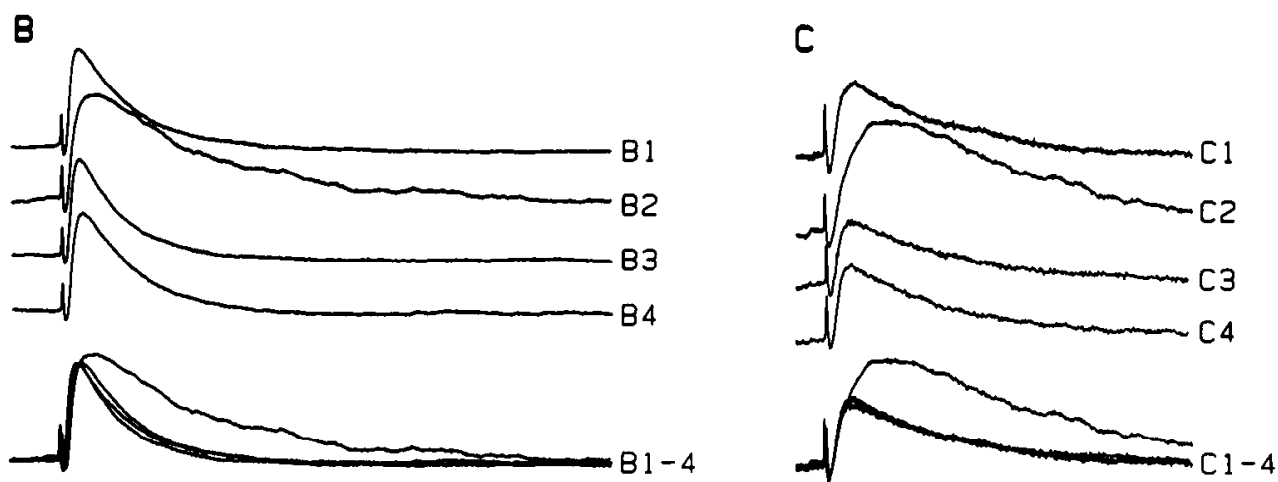

dry et al., 1984; Somogyi et al., 1984; Lin et al., 1986) of the cortex in vivo have demonstrated colocalization of GAD-like immunoreactivity with immunoreactivity for several different neuropeptides, including somatostatin, cholecystokinin, and neuropeptide $Y$. In the present study, we frequently recorded from neurons that produced monosynaptic IPSPs in their follower cells (see Table 1). IPSPs reversed polarity when the follower neuron was hyperpolarized, and they gradually became depolarizing potentials when microelectrodes containing $\mathrm{Cl}^{-}$were used to impale follower cells (data not shown). Addition of 10 $20 \mu \mathrm{M}$ bicuculline methiodide to the bathing medium invariably eliminated the IPSPs (16/16), as shown in Figure 9. These observations suggest that the IPSPs were mediated by the GABA receptor.

Most of the neurons that evoked monosynaptic IPSPs did not elicit any longer-latency synaptic activity; however, in a few cases $(4 / 21)$ the monosynantic IPSP was reliably followed by a burst of excitatory potentials. To elucidate the origin of this long-latency excitation, we performed experiments of the kind illustrated in Figure 10. Figure $10 \mathrm{~A}$ shows that an action potential in cell 1 produces an IPSP in cell 2 . The IPSP latency is $2.2 \mathrm{msec}$. At longer latency, excitatory potentials are observed in both cells. Addition of $3 \mathrm{~mm}$ kynurenic acid to the perfusion medium eliminates the excitatory potentials (Fig. 10B), but does not abolish the IPSP, thus confirming that it is monosynaptic. The long-latency activity returns when the culture is washed with normal medium (Fig. 10C). Perfusion of the culture with $20 \mu \mathrm{M}$ bicuculline blocks both the monosynaptic IPSP and the polysynaptic excitation (Fig. 10D). This observation suggests that the long-latency excitation in this case does not result from activation of $\mathrm{GABA}_{\mathrm{B}}$ receptors or from the corelease of an excitatory peptide. Blockade by bicuculline implies that the longlatency excitation is a secondary effect resulting from the in- hibitory action of GABA. One possible explanation for the generation of long-latency excitation by inhibitory neurons would be via a disinhibition mechanism. For example, it may be that in Figure 10 cell 1 synapsed on other inhibitory neurons on the island that were providing chronic inhibition to an excitatory cell. In such a case, stimulation of cell 1 could relieve the chronic inhibition of the excitatory cell and allow it to fire, thus triggering the long-latency excitation.

Since, as mentioned above, many GABA neurons in the cortex have peptides colocalized in them, we attempted to detect possible postsynaptic actions of such peptides. To improve the likelihood of observing an effect of peptides that might be released from GABAergic terminals, we activated inhibitory cells with brief trains of repetitive stimulation $(10-50 \mathrm{~Hz}$ for $1-5 \mathrm{sec}$; Willard and Nishi, 1985). In medium containing bicuculline, which blocked the IPSPs, we did not observe any consistent changes either in the resting potential or the input resistance of follower neurons. In control medium, without bicuculline, trains of high-frequency stimulation did not alter the GABA-mediated IPSPs. Thus, no effect attributable to peptides that might be colocalized with GABA was detected. We have not tested for effects on voltage-sensitive properties of follower cells.

In addition to forming synapses on nearby follower neurons, many of the inhibitory cells grown on island cultures (13/21) also made synaptic connections on themselves (referred to as autapases; Van Der Loos and Glaser, 1972). Evidence for inhibitory autapses can be seen in Figures 9 and 10. In Figure 9, $A, C$, and Figure $10 B$, autaptic IPSPs are superimposed on the undershoot of the inhibitory neuron's action potential. Perfusion with bicuculline methiodide reduced the depth of the undershoot in each cell (Fig. $9 B$ and Fig. 10D). Further evidence for inhibitory autapses came from recordings obtained with electrodes containing $\mathrm{KCl}$. When inhibitory neurons $(n=3)$ were 


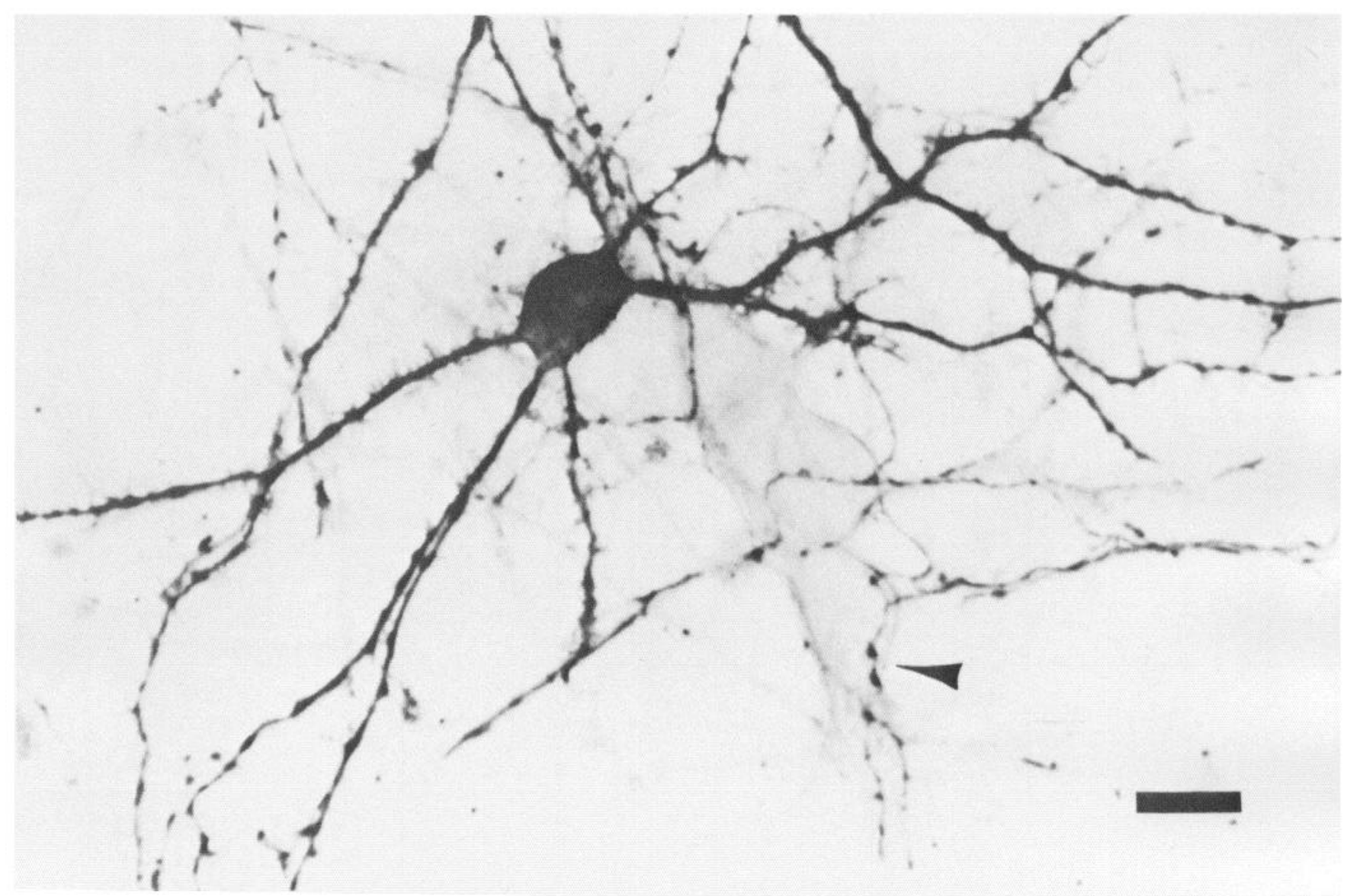

Figure 8. Immunohistochemical localization of GABA-like immunoreactivity. Cultures were prepared from an 8-d-old animal and fixed after 29 $\mathrm{d}$ in vitro. Several varicosities (arrowhead) are in close contact with the soma of an unstained neuron. Bar, $20 \mu \mathrm{m}$.

impaled with electrodes containing $\mathrm{Cl}^{-}$, they gradually developed depolarizing synaptic potentials that followed each action potential and were blocked by bicuculline (data not shown).

\section{Action potentials of excitatory and inhibitory neurons}

Over the course of our experiments, we observed that inhibitory neurons had distinctly narrower action potentials than did excitatory cells. Inhibitory neurons also displayed afterhyperpolarizations that were substantially larger than those of excitatory cells; however, this difference was not systematically examined since in many records the afterhyperpolarization was contaminated by synaptic potentials. Figure 11 illustrates several superimposed action potentials recorded from excitatory and inhibitory neurons. Analysis of action potentials from all neurons that could be reliably classified as either excitatory or inhibitory revealed that there were significant differences between the 2 populations (Table 3). Histograms of action potential width at half-height are shown in Figure 12. The width at half-height values obtained for inhibitory cells did not overlap with the values of excitatory neurons. This finding suggests that, under these same recording conditions, it should be possible to identify reliably excitatory and inhibitory neurons on the basis of action potential width.

\section{Discussion}

Dissociated cell cultures provide a convenient system for biochemical and physiological studies of neuronal function. Re- cently, several laboratories (see references in Honig and Hume, 1986, and O'Brien and Fischbach, 1986a) have used retrogradely transported fluorescent markers to identify specific subpopulations of living neurons in long-term culture. We have previously reported that identified corticocollicular neurons obtained from the visual cortex of young postnatal rats survive in dissociated cell culture and display many normal morphological and physiological properties (Huettner and Baughman, 1986b). In this paper, we have examined the pharmacology of synapses formed by corticocollicular cells with other unlabeled, unidentified cortical neurons.

Four well-characterized antagonists of excitatory amino acid receptors were employed in this study. APV is a selective antagonist of the NMDA class of glutamate receptor (Davies et al., 1981b), while kynurenic acid (Ganong et al., 1983; Jahr and Jessell, 1985), PDA (Davies et al., 1981a), and DGG (Davies and Watkins, 1981; O'Brien and Fischbach, 1986b) block both the NMDA and non-NMDA receptor subtypes. Perfusion of cultures with medium containing kynurenic acid, PDA, or DGG at 0.1-3 mM reduced or abolished monosynaptic EPSPs produced by all of the labeled corticocollicular driver neurons and by all but one of the unlabeled excitatory cortical cells. Similar effects of these drugs have been observed on EPSPs in the spinal cord (Jahr and Jessell, 1985; Nelson et al., 1986; O'Brien and Fischbach, 1986c) and hippocampus (Collingridge et al., 1983; Crunelli et al., 1983; Cotman et al., 1986), where their action is known to be postsynaptic. The blockade of monosynaptic 

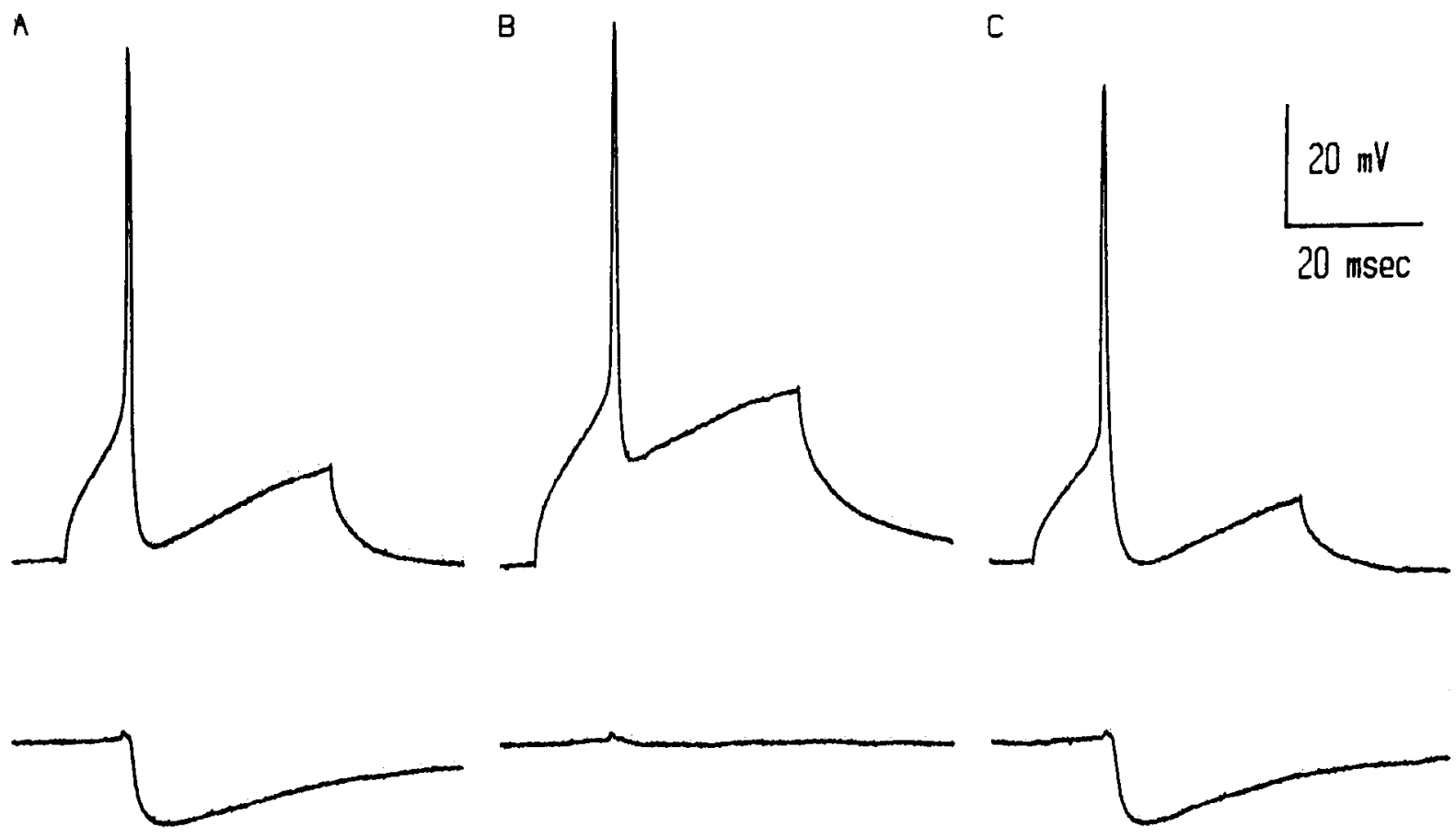

\section{UM BICUCULLINE}

Figure 9. Effect of bicuculline methiodide on a monosynaptic IPSP. $A-C$, An unlabeled neuron (upper trace) was stimulated to fire an action potential. The bottom trace shows the postsynaptic response in a nearby, unlabeled follower cell before $A$, during $B$, and after $C$ superfusion with $20 \mu \mathrm{M}$ bicuculline methiodide. The recordings were obtained from neurons on an island culture $16 \mathrm{~d}$ after plating. The resting potential of the inhibitory driver neuron was $-64 \mathrm{mV}$, while the resting potential of the follower cell was $-56 \mathrm{mV}$.

EPSPs by kynurenic acid, PDA, and DGG strongly suggests that the fast excitatory synapses in our cultures are mediated by a transmitter that acts on glutamate receptors.

\section{EPSPs exhibit 2 components}

In order to determine the role played by each of the glutamate receptor subtypes, cultures were perfused with the NMDA receptor antagonist APV. Because responses to NMDA are known to be antagonized by physiological levels of $\mathrm{Mg}^{2+}$ (Mayer and Westbrook, 1985), we examined the effects of APV both in $\mathrm{Mg}^{2+}$-free solutions as well as in our normal recording medium, which contained $1 \mathrm{~mm} \mathrm{Mg}^{2+}$. In medium with physiological levels of $\mathrm{Ca}^{2+}$ and $\mathrm{Mg}^{2+}\left(2 \mathrm{mM} \mathrm{Ca} \mathrm{Ca}^{21} / 1 \mathrm{mM} \mathrm{Mg}^{2+}\right.$ ), we found that APV reduced the level of polysynaptic excitation, but had very little effect on the amplitude and time course of monosynaptic EPSPs. These findings are largely in agreement with earlier work (Collingridge et al., 1983; Crunelli et al., 1983; Davies and Watkins, 1983; Jahr and Yoshioka, 1986) in other systems. When cultures were perfused with $\mathrm{Mg}^{2+}$-free medium, however, we observed that the falling phase of monosynaptic EPSPs became significantly prolonged, and that APV completely antagonized this prolongation. This finding suggests that excitatory synaptic

Table 3. Electrophysiological parameters of cortical neurons

\begin{tabular}{lccc} 
Parameter & $\begin{array}{l}\text { Inhibitory neurons } \\
(n=18)\end{array}$ & $\begin{array}{l}\text { Unlabeled excitatory } \\
\text { neurons } \\
(n=51)\end{array}$ & $\begin{array}{l}\text { Corticocollicular } \\
\text { neurons } \\
(n=46)\end{array}$ \\
\hline Resting potential $(\mathrm{mV})$ & $-65 \pm 8$ & $-67 \pm 7$ & $-65 \pm 9$ \\
Input resistance $(\mathrm{M} \Omega)$ & $180 \pm 80$ & $150 \pm 41$ & $181 \pm 80$ \\
Spike height $(\mathrm{mV})$ & $86 \pm 8$ & $90 \pm 11$ & $90 \pm 11$ \\
Spike width $(\mathrm{msec})$ & $1.0 \pm 0.14^{*}$ & $2.0 \pm 0.47$ & $2.2 \pm 0.55$ \\
Rate of rise $(\mathrm{V} / \mathrm{sec})$ & $162 \pm 35$ & $138 \pm 58$ & $128 \pm 59$ \\
Rate of fall $(\mathrm{V} / \mathrm{sec})$ & $55 \pm 14^{*}$ & $28 \pm 9$ & $24 \pm 8$
\end{tabular}

All entries represent means \pm SD. Input resistance was determined by injecting small pulses of current that hyperpolarized the membrane by $5-10 \mathrm{mV}$. Action potentials were triggered with depolarizing current. The spike width was measured at half the action potential height. Rate of rise and rate of fall represent maximum values during the rising and falling phases of the action potential, respectively. All recordings were obtained from neurons on island cultures.

* Differences among the mcans for spike width and rate of fall significant at the $p<0.01$ level (ANOVA; $F$ statistic). For the other parameters, differences among the means are not significant at the $p<0.05$ level. Tukey-Kramer confidence intervals indicate that the differences in mean spike width and mean rate of fall between inhibitory neurons and unlabeled excitatory neurons or corticocollicular cells are significant at the $p<0.01$ level. 


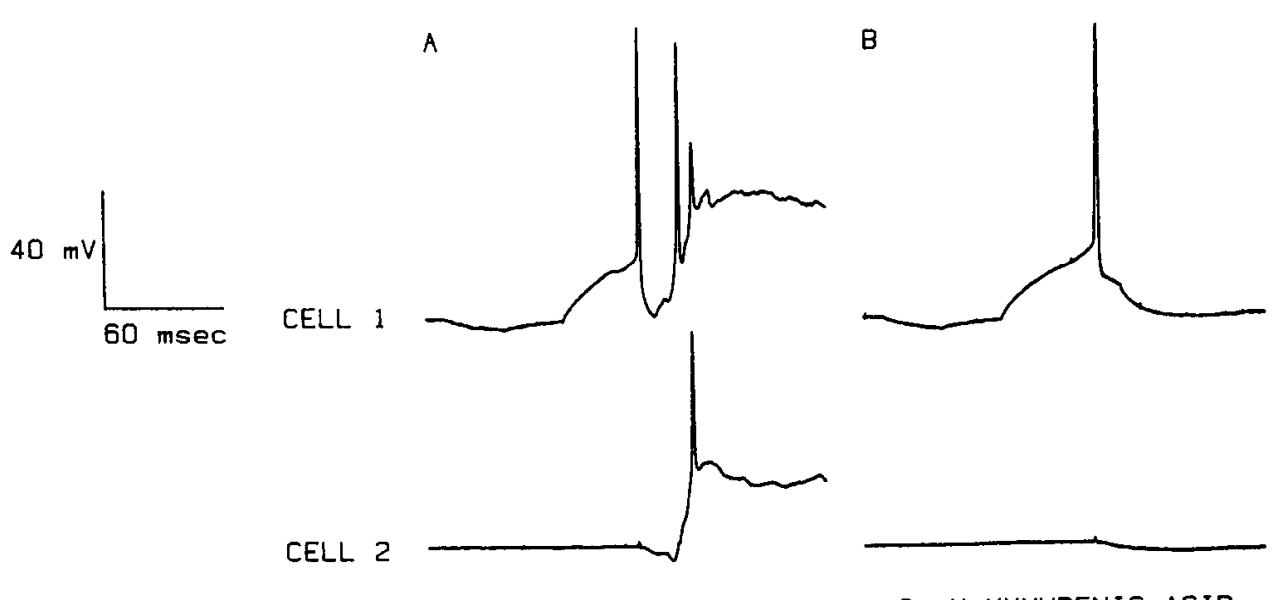

$3 \mathrm{mM} \mathrm{KYNURENIC} \mathrm{ACID}$
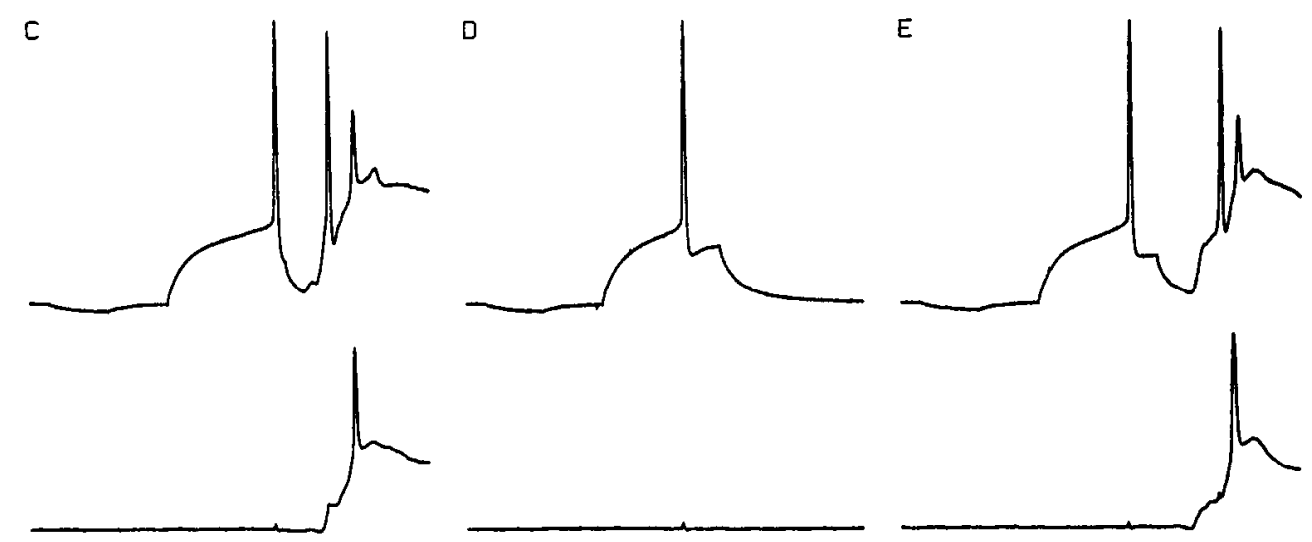

WASH

20 UM BICUCULLINE

WASH

Figure 10. Effect of kynurenic acid and bicuculline methiodide on a compound postsynaptic response. $A$, Stimulation of cell 1 evoked a shortlatency IPSP in cell 2 and produced long-latency excitation in both neurons. $B$, Superfusion of the culture with 3 mm kynurenic acid reversibly blocked the excitation but did not affect the IPSP. $D$, Superfusion with $20 \mu \mathrm{M}$ bicuculline methiodide reversibly abolished both the IPSP and the long-latency excitation. The recordings were obtained from 2 unlabeled neurons on an island culture $18 \mathrm{~d}$ after plating. The resting potential of cell 1 was $-62 \mathrm{mV}$, while that of cell 2 was $-68 \mathrm{mV}$.

transmission between cortical neurons involves activation of both NMDA and non-NMDA receptors. In $1 \mathrm{mM} \mathrm{Mg}^{2+}$, EPSPs had relatively fast rising and falling phases and were predominantly mediated by non-NMDA receptors. In $\mathrm{Mg}^{2+}$-free medium, on the other hand, NMDA receptors contributed a slow component to the EPSP. Similar conclusions have been reached by Dale and colleagues (Dale and Roberts, 1985; Dale and Grillner, 1986) in recent studies of excitatory transmission in the spinal cord of Xenopus and lamprey, and by Forsythe and Westbrook (1986) in a study of mouse spinal cord neurons in culture. In addition to dual-component EPSPs, Dale and co-workers (Dale and Roberts, 1985; Dale and Grillner, 1986) found that in $\mathrm{Mg}^{2+}$-free solutions some cells exhibited EPSPs that had a slow rise time and were completely blocked by APV. All of our recordings were initiated in medium containing $\mathrm{Mg}^{2+}$, and we studied only pairs that exhibited a fast monosynaptic EPSP from the outset. It would be of interest to see whether some of the driver neurons that we classified as null in our normal recording solution might produce a slow EPSP in $\mathbf{M g}^{2+}$-free medium.

Although the exact concentration of $\mathrm{Mg}^{2+}$ at central synapses is unknown, at typical physiological levels of $0.5-1 \mathrm{mM} \mathrm{Mg}^{2+}$, the contribution made by NMDA receptors to the PSP would

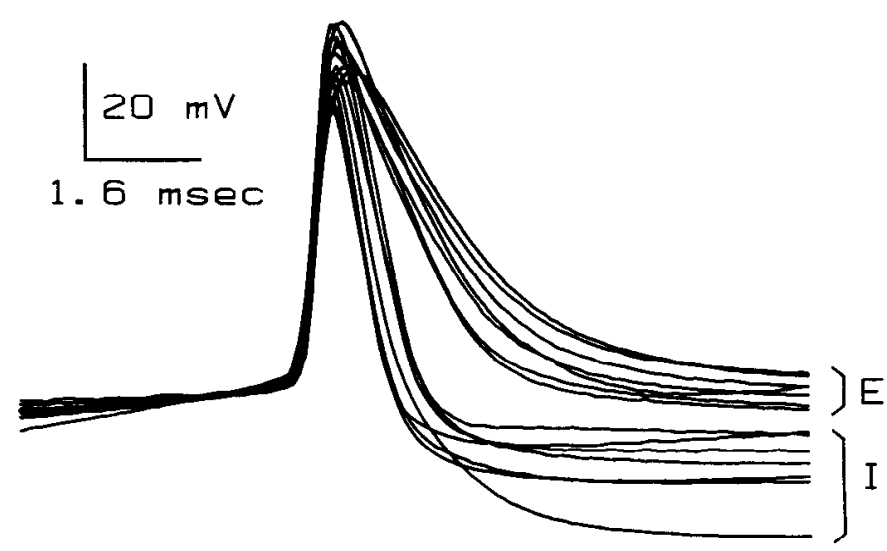

Figure 11. Action potentials of excitatory and inhibitory neurons. Superimposed action potentials recorded from 7 diffrent inhibitory neurons, labeled $I$, and from 7 different excitatory neurons, labeled $E$. Included in the excitatory population were 4 labeled corticocollicular neurons. All cells had resting potentials within -53 to $-69 \mathrm{mV}$. The traces were shifted slightly to align their threshold levels for clearer comparison. All of the recordings were obtained from neurons on island cultures. 


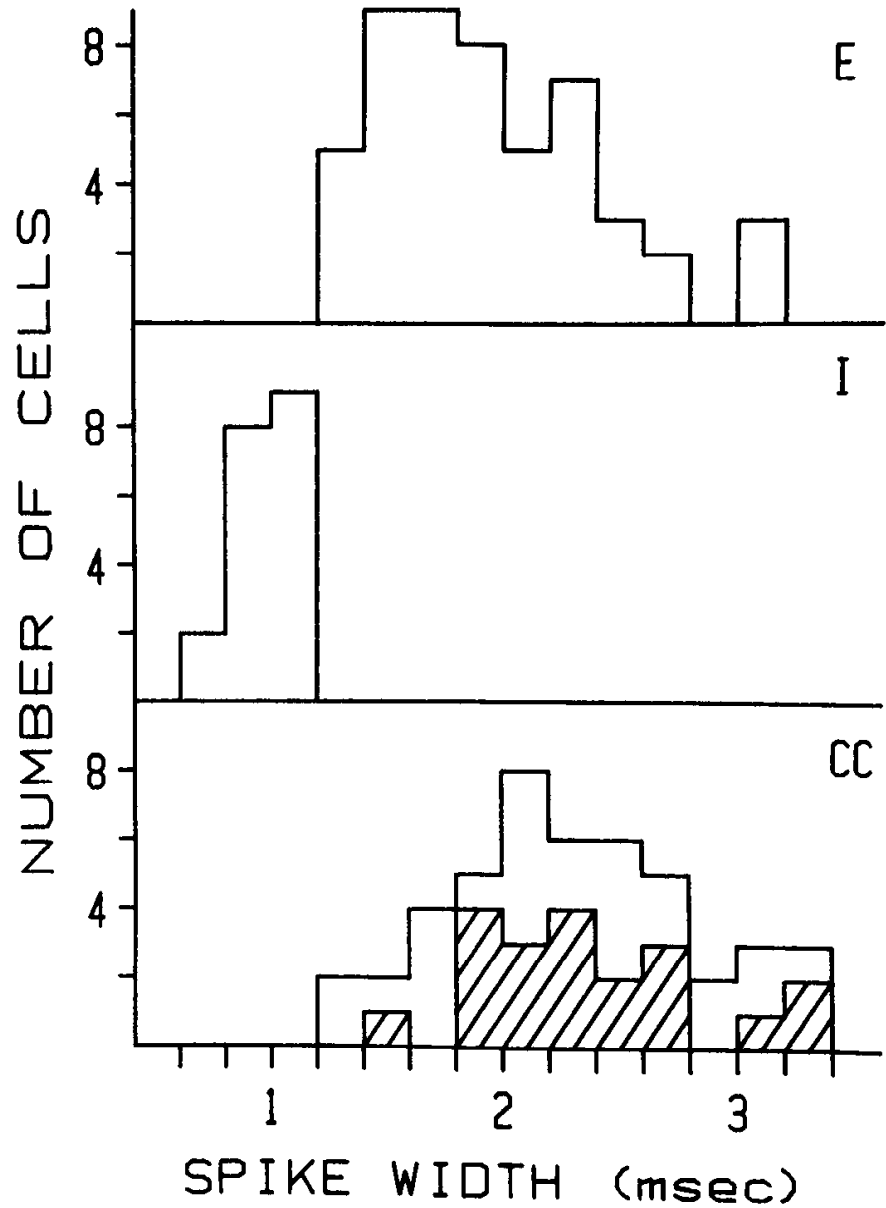

Figure 12. Histograms of action potential width at half-height for unlabeled excitatory $(E)$ and inhibitory $(I)$ neurons, and for labeled corticocollicular $(C C)$ neurons. In the histogram for corticocollicular neurons, striped bars represent labeled neurons that evoked monosynaptic EPSPs, while open bars indicate labeled neurons that did not elicit a postsynaptic response or that only evoked polysynaptic activity. All of the recordings were obtained from neurons on island cultures.

clearly be limited by $\mathrm{Mg}^{2+}$ blockade. Since the blocking action of $\mathrm{Mg}^{2+}$ is strongly voltage-dependent (Nowak et al., 1984; Mayer and Westbrook, 1985), the relative size of the slow component should vary with changes in the membrane potential of the follower cell. At membrane potentials of -60 to $-80 \mathrm{mV}$, NMDA receptors would contribute little to the EPSP, but when the follower cell is depolarized, the blockade by $\mathrm{Mg}^{2+}$ would be diminished. In slices of rat cerebral cortex, Thompson (1986) recorded an APV-sensitive EPSP that increased in amplitude as follower cells were depolarized. The voltage-dependence of spontaneous EPSPs received by chick motoneurons in culture (O'Brien and Fischbach, 1986c) is also consistent with a substantial contribution by NMDA receptors. However, other studies of EPSPs (Rothman and Samaie, 1985) and excitatory postsynaptic currents (Brown and Johnston, 1983; Nelson et al., 1986) as a function of voltage have not detected any component attributable to NMDA receptors. In our hands, depolarization of follower cells did not reveal any slow component of the EPSP such as that observed in $\mathrm{Mg}^{2+}$-free medium. Nevertheless, the fact that APV reduced the level of polysynaptic excitation suggests that, even in $1 \mathrm{mM} \mathrm{Mg}^{2+}$, NMDA receptors contribute to the postsynaptic response.

\section{Action potentials of excitatory and inhibitory neurons}

Recent studies of cortical neurons in cell culture (Nerbonne et al., 1985) and tissue slices (McCormick et al., 1985) have provided evidence that specific neuronal subpopulations possess unique electrophysiological properties. From recordings obtained with Lucifer yellow-filled electrodes, McCormick et al. (1985) concluded that cells with narrow, rapid action potentials were invariably nonpyramidal neurons, while cells with relatively slower, broader action potentials exhibited pyramidal morphology. These authors suggested that the cells with narrow action potentials were inhibitory interneurons because the morphology of their Lucifer yellow-filled cells closely matched the morphology of cortical neurons that possess GAD-like (Ribak, 1978) and GABA-like (Ottersen and Storm-Mathisen, 1984) immunoreactivity. In the present study, we have obtained direct evidence that inhibitory neurons in culture exhibit significantly narrower action potentials than do excitatory cells. The IPSPs produced by inhibitory neurons were completely antagonized by bicuculline, which suggests that GABA is the inhibitory transmitter released by these cells. The difference in action potential properties between excitatory and inhibitory cells is likely to be due to the ionic currents expressed by each cell type. Wholecell voltage-clamp recordings obtained from cortical neurons in culture (Nerbonne et al., 1985; Nerbonne and Burkhalter, 1986) should allow for a full characterization of the ionic current present in specific cell classes.

\section{Corticocollicular neurons in vivo and in vitro}

The projection from visual cortex to the superior colliculus arises from a well-described population of pyramidal neurons with cell bodies in cortical layer V (Gilbert and Kelly, 1975; Sefton et al., 1981). In the cat and monkey, these cells exhibit complex receptive fields (Palmer and Rosenquist, 1974; Finlay et al., 1976; Weyand et al., 1986) and contribute to the binocular and directional responses of collicular cells (Wickelgren and Sterling, 1969). Although less well studied, corticocollicular neurons in the rat apparently share some of these physiological characteristics (Schofield et al., 1985). In addition to their subcortical projection, many corticocollicular neurons also possess extensive axon collaterals that innervate nearby areas of the visual cortex (Schofield et al., 1985). In vivo, corticocollicular neurons, as well as most other pyramidal cells, are thought to be excitatory (LeVay, 1973; Lund-Karlsen and Fonnum, 1978; Jones, 1986). In culture, we found that monosynaptic responses evoked by stimulation of labeled corticocollicular neurons were exclusively excitatory, while unlabeled cortical cells produced either excitatory or inhibitory potentials. In addition, the time courses of the action potentials of all of the corticocollicular neurons from which we recorded were characteristic of excitatory neurons. These results suggest that the corticocollicular neurons maintain several important phenotypic properties when grown in dissociated culture.

Our pharmacological experiments have shown that corticocollicular neurons in culture use an excitatory amino acid neurotransmitter. Several lines of evidence suggest that this may also be true in vivo. Ablation of the visual cortex produces a dramatic drop in the endogenous levels of glutamate in the superior colliculus (Lund-Karlsen and Fonnum, 1978). Uptake (Fosse et al., 1984) and release (Fosse et al., 1986) of glutamate by slices of superior colliculus are also diminished following 
visual cortex ablation. In addition, large pyramidal neurons in layer $\mathrm{V}$ of neocortex, which are likely to include corticocollicular cells, possess marked immunoreactivity for glutamate (Ottersen and Storm-Mathisen, 1984; Madl et al., 1986) and for glutaminase (Donoghue et al., 1985), an enzyme involved in glutamate biosynthesis. It should be noted, however, that antisera raised against glutamate also stain many neurons that are unlikely to use glutamate as a transmitter (Ottersen and Storm-Mathisen, 1984).

Retrograde labeling with ${ }^{3} \mathrm{H}-\mathrm{D}$-aspartate has also been proposed as a selective marker for neurons using an excitatory amino acid transmitter (for review, see Cuenod and Streit, 1983). Neurons accumulate ${ }^{3} \mathrm{H}-\mathrm{D}$-aspartate by the same high-affinity system that is responsible for uptake of the L-forms of glutamate and aspartate (Davies and Johnston, 1976). In contrast to the L-amino acids, however, D-aspartate is not metabolized, and it thus provides a good marker for autoradiographic labeling. In a study of the major visual pathways in the cat, Baughman and Gilbert (1981) found that pyramidal cells in layer VI, which project to the lateral geniculate nucleus (LGN), were strongly labeled following injections of ${ }^{3} \mathrm{H}-\mathrm{D}$-aspartate into the LGN, while corticocollicular neurons in layer $\mathrm{V}$ were not labeled after injections into the superior colliculus. Subsequent work (Matute and Streit, 1985) has confirmed this finding in the cat visual cortex, but has revealed that corticocollicular neurons in the rat and rabbit, as well as in other cortical areas in the cat, do in fact become labeled following ${ }^{3} \mathrm{H}$-D-aspartate injections into the superior colliculus. Baughman and Gilbert (1981) have suggested that passive diffusion within the axon may play a significant role in the retrograde movement of ${ }^{3} \mathrm{H}$-D-aspartate from the injection site to the cell body. Since the projection from area 17 to the superior colliculus in the cat is one of the longest such pathways studied, diffusion may not provide for an accumulation of ${ }^{3} \mathrm{H}$-D-aspartate in the cell soma that is sufficient to be detected. On the other hand, it may be that corticocollicular cells in the cat visual cortex simply lack the high-affinity uptake system for glutamate and aspartate. It is clear that not all excitatory neurons in cortical afferent and efferent pathways are labeled with ${ }^{3} \mathrm{H}$-D-aspartate. For example, relay neurons in the LGN are not labeled with ${ }^{3} \mathrm{H}$-D-aspartate following local injections into the LGN or following injections at their terminals in layer IV in striate cortex (Baughman and Gilbert, 1981). However, a recent pharmacological study in vivo obtained evidence that postsynaptic responses in the cortex to LGN input are mediated by excitatory amino acid receptors (Tsumoto et al., 1986). The evidence at this point suggests that cells labeled by ${ }^{3} \mathrm{H}-\mathrm{D}$-aspartate are likely to use an excitatory amino acid as their transmitter, while excitatory amino acids may or may not play a transmitter role in cell types that are not labeled by ${ }^{3} \mathrm{H}-\mathrm{D}-$ aspartate.

One final point that should be considered is the possibility of transmitter phenotype plasticity. A substantial body of work (Patterson, 1978; Potter et al., 1986) has demonstrated that synpathetic neurons in culture undergo changes in their transmitter status as a result of specific culture conditions. This finding suggests that it is unsafe to assume that the transmitter used by a neuron after several weeks in culture necessarily reflects the transmitter status that the neuron expressed in vivo. In the present study, we first recorded PSPs within $36-48 \mathrm{hr}$ after cells were plated, and the pharmacology of EPSPs was evaluated after $2-54 \mathrm{~d}$ in vitro. While the amplitude and complexity of polysynaptic interactions increased greatly as the cultures matured, the basic finding that corticocollicular neurons were excitatory and that the EPSPs they produced were blocked by excitatory amino acid receptor antagonists was consistently observed at all time points in vitro. If the corticocollicular neurons changed their transmitter status in culture, they must have done so completely within the first $2 \mathrm{~d}$ in vitro, which seems unlikely.

This study has examined the properties of a specific, identified subpopulation of neurons from the rat visual cortex. The availability of a permanent label, such as the fluorescent latex microspheres (Katz et al., 1984) employed here, is critical for this type of investigation in long-term culture. Although the projection from visual cortex to the superior colliculus is recognized as one of the major visual pathways, corticocollicular neurons represent only $1-2 \%$ of all neurons within the rat's cortex. Without an unambiguous method for identifying corticocollular neurons, there would be no way to assess their survival or to study them selectively. Our recordings have shown that the synapses formed by corticocollicular neurons have the same pharmacology as synapses made by most other excitatory cortical neurons in culture. While the chemical identity of the excitatory transmitter remains to be determined, it is likely to be an excitatory amino acid.

\section{References}

Anderton, B. H., R. Thorpe, J. Cohen, S. Selvendran, and P. Woodhams (1980) Specific neuronal localization by immunofluorescence of 10 nm filament polypeptides. J. Neurocytol. 9: 835-844.

Barker, J. L., and B. R. Ransom (1978) Amino acid pharmacology of mammalian central neurones grown in tissue culture. J. Physiol. (Lond.) 280: 331-354.

Baughman, R., and C. D. Gilbert (1981) Aspartate and glutamate as possible neurotransmitters in the visual cortex. J. Neurosci. 1: 427439.

Bornstein, M. B. (1958) Reconstituted rat-tail collagen used as a substrate for tissue cultures on coverslips in maximow slides and roller tubes. Lab. Invest. 7: 134

Bray, D. (1970) Surface movements during the growth of single explanted neurons. Proc. Natl. Acad. Sci. USA 65: 905-910.

Brown, T. H., and D. Johnston (1983) Voltage-clamp analysis of mossy fiber synaptic input to hippocampal neurons. J. Neurophysiol. 50 : 487-507.

Choi, D. W., and G. D. Fischbach (1981) GABA conductance of chick spinal cord and dorsal root ganglion neurons in cell culture. J. Neurophysiol. 45: 605-620.

Collingridge, G. L., S. J. Kehl, and H. McLennan (1983) Excitatory amino acids in synaptic transmission in the Schaffer collateral-commissural pathway of the rat hippocampus. J. Physiol. (Lond.) 334: 33-46.

Cotman, C. W., J. A. Flatman, A. H. Ganong, and M. N. Perkin (1986) Effects of excitatory amino acid antagonists on evoked and spontaneous excitatory potentials in guinea-pig hippocampus. J. Physiol. (Lond.) 378: 403-415.

Crunelli, V., S. Forda, and J. S. Kelly (1983) Blockade of amino acidinduced depolarizations and inhibition of excitatory post-synaptic potentials in rat dentate gyrus. J. Physiol. (Lond.) 341: 627-640.

Cuenod, M., and P. Streit (1983) Neuronal tracing using retrograde migration of labeled transmitter-related compounds. In Methods in Chemical Neuroanatomy, A. Björklund and T. Hökfelt, eds., pp. 365397, Elsevier, Amsterdam.

Dale, N., and S. Grillner (1986) Dual-component synaptic potentials in the lamprey mediated by excitatory amino acid receptors. J. Neurosci. 6: 2653-2661.

Dale, N., and A. Roberts (1985) Dual-component amino-acid-mediated synaptic potentials: Excitatory drive for swimming in Xenopus embryos. J. Physiol. (Lond.) 363: 35-59.

Davies, J., and J. C. Watkins (1981) Differentiation of kainate and quisqualate receptors in the cat spinal cord by selective antagonism with $\gamma$-D(and L)-glutamylglycine. Brain Res. 206: 172-177.

Davies, J., and J. C. Watkins (1983) Role of excitatory amino acid 
receptors in mono- and polysynaptic excitation in the cat spinal cord. Exp. Brain Res. 49: 280-290.

Davies, J., K. H. Evans, A. A. Francis, A. W. Jones, and J. C. Watkins (1981a) Antagonism of excitatory amino acid-induced and synaptic excitation of spinal neurones by cis-2,3-piperidine dicarboxylate. J. Neurochem. 100: 1305-1307.

Davies, J., A. A. Francis, A. W. Jones, and J. C. Watkins (1981b) 2-Amino-5-phosphonovalerate (2APV), a potent and selective antagonist of amino acid-induced and synaptic excitation. Neurosci. Lett. $21: 77-81$

Davies, L. P., and G. A. R. Johnston (1976) Uptake and release of Dand L-asparatate by rat brain slices. J. Neurochem. 26: 1007-1014.

Dichter, M. A. (1980) Physiological identification of GABA as the inhibitory transmitter for cortical neurons in cell culture. Brain Res. 190: 111-121.

Donoghue, J. P., R. J. Wenthold, and R. A. Altschuler (1985) Localization of glutaminase-like and aspartate aminotransferase-like immunoreactivity in neurons of cerebral neocortex. J. Neurosci. 5: 25972608.

Dunlap, K., and G. D. Fischbach (1978) Neurotransmitters decrease the calcium component of sensory neurone action potentials. Nature 276: $837-839$.

Finlay, B. L., P. H. Schiller, and S. F. Volman (1976) Quantitative studies of single-cell properties in monkey striate cortex. IV. Corticotectal cells. J. Neurophysiol. 39: 1352-1361.

Forsythe, I. D., and G. L. Westbrook (1986) Monosynaptic activation of NMDA receptors in mouse spinal cord cultures. Soc. Neurosci. Abstr. 12: 62.

Fosse, V. M., P. Heggelund, E. Iversen, and F. Fonnum (1984) Effects of area 17 ablation on neurotransmitter parameters in efferents to area 18 , the lateral geniculate body, pulvinar and superior colliculus in the cat. Neurosci. Lett. 52: 323-328.

Fosse, V. M., J. Kolstad, and F. Fonnum (1986) A bioluminescence method for the measurement of L-glutamate: Applications to the study of changes in the release of L-glutamate from lateral geniculate nucleus and superior colliculus after visual cortex ablation in rats. J. Neurochem. 47: 340-349.

Foster, A. C., and G. E. Fagg (1984) Acidic amino acid binding sites in mammalian neuronal membranes: Their characteristics and relationship to synaptic receptors. Brain Res. Rev. 7: 103-164.

Frankenhaeuser, B., and A. L. Hodgkin (1957) The action of calcium on the electrical properties of squid axons. J. Physiol. (Lond.) 137 218-244.

Furshpan, E. J., P. R. MacLeish, P. H. O'Lague, and D. D. Potter (1976) Chemical transmission between rat sympathetic neurons and cardiac myocytes developing in microcultures: Evidence for cholinergic, adrenergic, and dual-function neurons. Proc. Natl. Acad. Sci. USA 73 . 4225-4229.

Furshpan, E. J., S. C. Landis, S. G. Matsumoto, and D. D. Potter (1986) Synaptic function in rat sympathetic neurons in microcultures. I. Secretion of norepinephrine and acetylcholine. J. Neurosci. 6: 10611079.

Ganong, A. H., T. H. Lanthorn, and C. W. Cotman (1983) Kynurenic acid inhibits synaptic and acidic amino acid-induced responses in the rat hippocampus and spinal cord. Brain Res. 273: 170-174.

Gilbert, C. D., and J. P. Kelly (1975) The projections of cells in different layers of the cat's visual cortex. J. Comp. Neurol. 163: 81106.

Hayashi, T. (1954) Effects of sodium glutamate on the nervous system. Keio J. Med. 3: 183-192.

Hendry, S. H., E. G. Jones, J. DeFelipe, D. Schmechel, C. Brandon, and P. C. Emson (1984) Neuropeptide containing neurons of the cerebral cortex as also GABAergic. Proc. Natl. Acad. Sci. USA 81 6526-6530.

Herron, C. E., R. A. J. Lester, E. J. Coan, and G. L. Collingridge (1985) Intracellular demonstration of an $N$-methyl-D-aspartate receptor mediated component of synaptic transmission in the rat hippocampus Neurosci. Lett. 60: 19-23.

Honig, M. G., and R. I. Hume (1986) Fluorescent carbocyanine dyes allow living neurons of identified origin to be studied in long-term cultures. J. Cell Biol. 103: 171-187.

Huettner, J. E., and R. W. Baughman (1986a) Pharmacology of excitatory synapses formed by identifed neurons in primary cultures of rat visual cortex. Soc. Neurosci. Abstr. 12:957.
Huettner, J. E., and R. W. Baughman (1986b) Primary culture of identified neurons from the visual cortex of postnatal rats. J. Neurosci. 6: 3044-3060.

Jahr, C. E., and T. M. Jessell (1985) Synaptic transmission between dorsal root ganglion and dorsal horn neurons in culture: Antagonism of monosynaptic excitatory postsynaptic potentials and glutamate excitation by kynurenate. J. Neurosci. 5: 2281-2289.

Jahr, C. E., and K. Yoshioka (1986) Ia afferent excitation of motoneurones in the in vitro new-born rat spinal cord is selectively antagonized by kynurenate. J. Physiol. (Lond.) 370: 515-530.

Jones, E. G. (1986) Neurotransmitters in the cerebral cortex. J. Neurosurg. 65: 135-153.

Katz, L. C., A. Burkhalter, and W. J. Dreyer (1984) Fluorescent latex microspheres as a retrograde neuronal marker for in vivo and in vitro studies of visual cortex. Nature 310:498-500.

Krnjevic, K., and J. W. Phillis (1963) Iontophoretic studies of neurones in the mammalian cerebral cortex. J. Physiol. (Lond.) 165:274304.

Krnjevic, K., and S. Schwartz (1967) The action of $\gamma$-aminobutyric acid on cortical neurones. Exp. Brain Res. 3: 320-336.

LeVay, S. (1973) Synaptic patterns in the visual cortex of the cat and monkey. Electron microscopy of Golgi preparations. J. Comp. Neurol. 150: 53-86.

Lin, C. S., S. M. Lu, and D. E. Schmechel (1986) Glutamic acid decarboxylase and somatostatin immunoreactivities in rat visual cortex. J. Comp. Neurol. 244: 369-383.

Lund-Karlsen, R., and F. Fonnum (1978) Evidence for glutamate as a neuro-transmitter in the corticofugal fibers to the dorsal lateral geniculate body and the superior colliculus in rats. Brain Res. 151 : 457-467.

Madl, J. E., A. A. Larson, and A. J. Beitz (1986) Monoclonal antibody specific for carbodiimide-fixed glutamate: Immunocytochemical localization in the rat CNS. J. Histochem. Cytochem. 34: 317-326.

Matute, C., and P. Streit (1985) Selective retrograde labeling with D- ${ }^{3} \mathrm{H}$-aspartate in afferents to the mammalian superior colliculus. $\mathrm{J}$. Comp. Neurol. 241: 34-49.

Mayer, M. L., and G. L. Westbrook (1985) The action of $N$-methylD-aspartic acid on mouse spinal neurones in culture. J. Physiol. (Lond.) 361: 65-90.

McCormick, D. A., B. W. Connors, J. W. Lighthall, and D. A. Prince (1985) Comparative electrophysiology of pyramidaland sparselyspiny neurons of the neocortex. J. Neurophysiol. 54: 782-806.

Nelson, P. G., R. Y. K. Pun, and G. L. Westbrook (1986) Synaptic excitation in cultures of mouse spinal cord neurones: Receptor pharmacology and behavior of synaptic currents. J. Physiol. (Lond.) 372 : $169-190$

Nerbonne, J. M., and A. Burkhalter (1986) Properties of voltageactivated potassium currents in isolated, identified mammalian cortical neurons. Soc. Neurosci. Abstr. 12: 764.

Nerbonne, J. M., A. Burkhalter, and J. E. Huettner (1985) Electrophysiological characterization of identified, intrinsic cortical neurons in dissociated cell culture. Soc. Neurosci. Abstr. 11: 149.

Newberry, N. R., and R. A. Nicoll (1985) Comparison of the action of baclofen with $\gamma$-aminobutyric acid on rat hippocampal pyramida cells in vitro. J. Physiol. (Lond.) 360: 161-185.

Nowak, L., P. Bregestovski, P. Ascher, A. Herbet, and A. Prochiantz (1984) Magnesium gates glutamate-activated channels in mouse central neurones. Nature 307: 462-465.

O'Brien, R. J., and G. D. Fischbach (1986a) Isolation of embryonic chick motoneurons and their survival in vitro. J. Neurosci. 6: 32653274.

O'Brien, R. J., and G. D. Fischbach (1986b) Characterization of excitatory amino acid receptors expressed by embryonic chick motoneurons in vitro. J. Neurosci. 6: 3275-3283

O'Brien, R. J., and G. D. Fischbach (1986c) Excitatory synaptic transmission between interneurons and motoneurons in chick spinal cord cell cultures. J. Neurosci. 6: 3284-3289.

Ottersen, O. P., and J. Storm-Mathisen (1984) Glutamate- and GABAcontaining neurons in the mouse and rat brain, as demonstrated with a new immunocytochemical technique. J. Comp. Neurol. 229: 374392.

Palmer, L. A., and A. C. Rosenquist (1974) Visual receptive fields of single striate cortical units projecting to the superior colliculus in the cat. Brain Res. 67: 27-42. 
Patterson, P. H. (1978) Environmental determination of autonomic neurotransmitter functions. Annu. Rev. Neurosci. 1: 1-17.

Potter, D. D., S. C. Landis, S. G. Matsumoto, and E. J. Furshpan (1986) Synaptic function in rat sympathetic neurons in microcultures. II. Adrenergic/cholinergic dual status and plasticity. J. Neurosci. 6: 10801098.

Ribak, C. E. (1978) Aspinous and sparsely-spinous stellate neurons in the visual cortex of rats contain glutamic acid decarboxylase. J. Neurocytol. 7: 461-478.

Rothman, S. M., and M. Samaie (1985) Physiology of excitatory synaptic transmission in cultures of dissociated rat hippocampus. J. Neurophysiol. 54: 701-713.

Schofield, B. R., L. E. Hallman, and C. S. Lin (1985) Physiological and morphological properties of corticotectal cells in the hooded rat. Soc. Neurosci. Abstr. 11: 227

Sefton, A. J., A. Mackay-Sim, L. A. Baur, and L. J. Cottee (1981) Cortical projections to visual centers in the rat: An HRP study. Brain Res. 215: 1-13.

Snodgrass, S. R., W. F. White, B. Biales, and M. Dichter (1980) Biochemical correlates of GABA function in rat cortical neurons in culture. Brain Res. 190: 123-138.

Somogyi, P., A. J. Hodgson, A. D. Smith, M. G. Nunzi, A. Gorio, and J. Y. Wu (1984) Different populations of GABAergic neurons in the visual cortex and hippocampus of cat contain somatostatin- or cholccystokinin-immunorcactive material. J. Neurosci. 4: 2590-2603.

Streit, P. (1984) Glutamate and aspartate as transmitter candidates for systems of the cerebral cortex. In Cerebral Cortex, E. G. Jones and A. Peters, eds., pp. 119-143, Plenum, New York.
Thompson, A. M. (1986) A magnesium-sensitive post-synaptic potential in rat cerebral cortex resembles neuronal responses to $N$-methylaspartate. J. Physiol. (Lond.) 370: 531-549.

Tsumoto, T., H. Masui, and H. Sato (1986) Excitatory amino acid transmitters in neuronal circuits of the cat visual cortex. J. Neurophysiol. 55: 469-483.

Van Der Loos, H., and E. M. Glaser (1972) Autapses in neocortex cerebri: Synapses between a pyramidal cell's axon and its own dendrites. Brain Res. 48: 355-360.

Watkins, J. C., and R. H. Evans (1981) Excitatory amino acid transmitters. Annu. Rev. Pharmacol. Toxicol. 21: 165-204.

Weyand, T. G., J. G. Malpeli, C. Lee, and H. D. Schwark (1986) Cat area 17. IV. Two types of corticotectal cells defined by controlling geniculate inputs. J. Neurophysiol. 56: 1102-1108.

White, W. F., S. R. Snodgrass, and M. Dichter (1980) Identification of GABA neurons in rat cortical cultures by GABA uptake autoradiography. Brain Res. 190: 139-152.

Wickelgren, B. G., and P. Sterling (1969) Influence of visual cortex on receptive fields in the superior colliculus of the cat. J. Neurophysiol. 32: 16-23.

Willard, A. L., and R. Nishi (1985) Neurons dissociated from rat myenteric plexus retain differentiated properties when grown in cell culture III. Synaptic interactions and modulatory effects of neurotransmitter candidates. Neuroscience 16: 213-221.

Yellen, G. (1984) Ion effects on ion channels. In 1984 Short Course Syllabus: Molecular Mechanisms of Signaling Across Neuronal Membranes, Society for Neuroscience, Washington, DC, pp. 11-20. 